\title{
Transcriptome analysis reveals that multiple metabolic pathways operate in Zea mays roots subjected to graphene
}

\section{Zhiwen Chen ( $\sim$ b1301031@cau.edu.cn )}

Institute of Plant Physiology and Ecology Shanghai Institutes for Biological Sciences

https://orcid.org/0000-0002-0268-5942

Jianguo Zhao

Shanxi Datong University

Jie Song

Shanxi Datong University

Shenghua Han

Shanxi Datong University

Yaqin Du

Shanxi Datong University

Yuying Qiao

Shanxi Datong University

Zehui Liu

Shanxi Datong University

Jun Qiao

Shanxi Datong University

Weijia Li

Shanxi Datong University

Jingwei Li

Shanxi Datong University

Haiyan Wang

Shanxi Datong University

Baoyan Xing

Shanxi Datong University

Qiliang Pan

Shanxi Datong University

Research article 
Keywords: Zea mays L.; graphene; root architecture; N and K contents; transcriptome change; qPCR analysis

Posted Date: May 26th, 2020

DOI: https://doi.org/10.21203/rs.3.rs-29027/v1

License: (c) (1) This work is licensed under a Creative Commons Attribution 4.0 International License. Read Full License 


\section{Abstract}

Background: To explore the effects and molecular mechanism of graphene on the growth and development of Zea mays L., the seeds were randomly divided into the control and experimental groups in this study, the roots of Zea mays L. seedlings were watered by different concentrations $(0 \sim 100 \mathrm{mg} / \mathrm{L})$ graphene.

Results: By evaluating the root growth indices of maize, $50 \mathrm{mg} / \mathrm{L}$ graphene increased significantly the total root length, root volume, the number of root tips and root forks of maize seedlings compared with the control group. The contents of nitrogen and potassium in the soil around the roots were elevated after the treatment of $50 \mathrm{mg} / \mathrm{L}$ graphene. Then, we compared the transcriptome changes of Zea mays roots in response to $50 \mathrm{mg} / \mathrm{L}$ graphene treatment. Transcriptional factor regulation, plant hormone signal transduction, nitrogen and potassium metabolism as well as secondary metabolism in maize roots subjected to graphene showed significant up-regulated expressions, all of which might be related to mechanisms underlying graphene response. Based on QPCR validations, we proposed several candidate genes that might be responded to the graphene treatment in maize roots.

Conclusion: The transcriptional profiles presented here provide a foundation for deciphering the mechanism between the graphene and maize roots interaction.

\section{Background}

Nanomaterials have been widely used in the fields of electronics, machinery, energy and biomedicine [14]. Researchers showed that nanomaterials could improve seed germination rate and promote plant growth $[5,6]$. Nanomaterials mainly include metals, metal oxides, polymers and carbon nanoparticles, among which carbon nanomaterials have attracted extensive attention due to their unique chemical properties as well as low toxicity [6]. Graphene is a member of the carbon nanomaterials family, with the most promising engineered nanomaterials for its huge surface area, unparalleled mechanical property, electrical and thermal conductivity [7]. Graphene contains a large surface area, which carrying a variety of functional groups of oxygen-containing, including carboxyl, hydroxyl, and carbonyl groups to endow graphene higher water dispersity [8]. A myriad of studies proved that graphene both had positive and adverse effects on the growth and development processes in plants.

As to the positive effects of graphene on promoting the growth and development processes in plants, studies were mainly focused on the following aspects: firstly, graphene can promote the germination of plant seeds. Zhang et al. found that graphene-treated tomato seeds germinated much faster than control seeds, because of graphene penetrating seed husks to facilitate water uptake [9]. He et al. found that graphene could act as a water transporter in promoting germination of spinach seeds in soil [10]. In addition, hydrated graphene ribbon could promote aged seed germination of wheat [11]. Secondly, graphene could promote plant growth and development. Liu et al. found that graphene significantly increased the number of lateral roots and fresh weight of rice seedlings [12]. Zhang et al. found that 
graphene could regulate the synthesis of gibberellic acid in tomatoes and promote the roots growth of tomato seedlings [9]. Chakravarty et al. found that graphene significantly promoted the growth of roots, stems, leaves, flowers and fruits of cilantro and garlic, leading to elevated yield [13]. Anjum et al. found that graphene could improve the growth status of Vicia faba and promote the roots growth of Vicia faba [14]. Low concentration of sulfonated graphene could scavenge ROS in roots, altered root morphology and improve health state of maize seedlings [15]. Graphene activated the reproductive system of Gossypium hirsutum and Catharanthus roseus as well as reduced the toxic effects caused by drought and salt stresses [16]. Thirdly, recent researches indicated that graphene has the potential to act as a carrier to slowly release the fertilizer's effect and improve the utilization efficiency of nutrients [17-19]. Finally, graphene could inhibit the growth of pathogen of plants. For instance, He et al. found that graphene as an antibacterial agent could extend the vase life of cut flowers [20]. Wang et al. found that graphene presented antifungal effect for controlling Fusarium graminearum of wheat [21].

Apart from the positive effects, adverse effects on plants were also reported for concerning about the potential risk of graphene [22]. Current study reported that graphene has toxic effects on E. coli [23] and plants, such as inhibiting seedling growth in cabbage and tomatoes, inducing reactive oxygen species (ROS) production and cell death, and altering plant morphology [24]. High concentrations of graphene also inhibit the growth of rice, ultimately reducing its biomass [12]. Reduced graphene induced cytotoxicity and inhibits photosynthetic performance of the green alga [25]. Graphene also induced cell death in Arabidopsis thaliana [26,27], cadmium uptake, growth inhibition photosynthesis inhibition, and nutritional disorder in wheat seedlings $[28,29]$, cadmium uptake, $\mathrm{pH}$ alteration, iron overload and oxidative damage in rice [30,31], roots growth inhibition and oxidative stress in apple [32].

In general, it seems that positive effects of graphene on plants were at low concentrations while most studies of adverse effects were conducted at high concentrations graphene to study the acute toxicity in plant $[15,23,32]$. In rice plants, graphene absorbed into leaves could be converted into $\mathrm{CO}_{2}$ and released through mineralization [33], indication of the environmental fate of graphene in soil-plant system. The current progresses of researches were almost focused on the physiological and phenotypic data of plants, and has not been dissected from the level of molecular or gene evidence. This study explored the effects and molecular mechanism of graphene on the root growth and development of Zea mays L., we performed transcriptome expression profiles to clarify the effects of graphene on the roots of Zea mays seedling.

\section{Results}

\section{Characterization of graphene}

The ultraviolet-visible absorption spectrogram (Fig. 1A) shows a strong absorption peak at $270 \mathrm{~nm}$, which is a typical peak of graphene. Raman spectroscopy is a nondestructive and sensitive method of analysis of graphene and grapheme derivatives [34, 35]. Raman spectroscopy (Fig. 1B) shows that G peak appears near $1576 \mathrm{~cm}^{-1}$, which is generated by the stretching and far-moving of sp2 hybridized atoms in 
carbon rings or long chains, representing the ordered sp2 bond structure. Peak D appeared near $1348 \mathrm{~cm}^{-1}$, which was related to sp3 hybrid structure, representing defects and amorphous structure at the edge of graphene. A wide 2D peak appeared near $2707 \mathrm{~cm}^{-1}$, indicating that the number of graphene layers prepared was within 10 layers. High-resolution scanning electron microscopy (Fig. 1C) and transmission electron microscopy (Fig. 1D) showed that the graphene presented a transparent sheet structure with slightly wrinkled and undulate surface. The number of graphene layers prepared was 3-5 layers as observed under transmission electron microscopy.

\section{Exogenous Graphene Promoted The Growth And Development Of Maize}

Six concentration gradients $(0,20,25,33,50$ and $100 \mathrm{mg} / \mathrm{L})$ of graphene were used to treat maize seedling roots and irrigated through the roots. At the seedling stage, the phenotypes of maize plants were observed (Fig. 2). As shown in the Fig. 2, the graphene concentration of $50.00 \mathrm{mg} / \mathrm{L}$ could promote the growth of maize plants. Subsequently, we measured multiple physiological indexes to analyze the effect of graphene on the growth or development of maize plants.

\section{Exogenous graphene enhancedZea maysroot development}

Root architecture of maize seedlings under six concentration gradients of graphene $(0,20,25,33,50$ and $100 \mathrm{mg} / \mathrm{L}$ ) was investigated. The root growth and development of maize seedlings under graphene treatments were promoted, especially for the $50 \mathrm{mg} / \mathrm{L}$ graphene concentration (Fig. 3A). Root architecture, including total root length, total project area, total surface area, root volume, the number of root tips and root forks were measured (Fig. 3B-G). Compared to the control group, 25, 50 and $100 \mathrm{mg} / \mathrm{L}$ graphene increased the total root length (Fig. 3B), root volume (Fig. 3E), the number of root tips (Fig. 3F) and root forks (Fig. 3G) of maize seedlings. Total project area (Fig. 3C) and total surface area (Fig. 3D) were not affected by any of graphene treatment. $33 \mathrm{mg} / \mathrm{L}$ graphene promoted the number of root tips (Fig. 3F), but inhibited the development of total length (Fig. 3B). Among them, The maize seedlings treated with $50 \mathrm{mg} / \mathrm{L}$ graphene displayed significant higher values than CK (Fig. 3). Based on the above assay results, the $50 \mathrm{mg} / \mathrm{L}$ graphene concentration was used for the subsequent experiments and analyses.

\section{Transcriptome Sequencing}

To gain insights into how graphene might induce a promoting effect leading to enhanced root development, a comparative transcriptome analysis was performed. We collected root tissue samples from maize seedlings treated with $50 \mathrm{mg} / \mathrm{L}$ graphene $(X 100)$ and used untreated seedlings as the corresponding controls (CK). All samples were used for transcriptome sequencing with three biological replicates (Additional file 1: Table S1). In total, 170.02 million raw reads were obtained for the CK libraries 
(CK-1, CK-2 and CK-3), and 166.69 million raw reads were obtained for the X100 libraries (X100-1, X100-2 and $\mathrm{X} 100-3)$. After removing adapter and low-quality sequences along with contaminated reads, $24.15 \mathrm{~Gb}$ and $23.92 \mathrm{~Gb}$ high-quality clean bases remained from the CK and X100 libraries, respectively (Table S1). Using the $Z$. mays genome of B73 [36], the number of total clean reads was 43.67-60.13 million for the CK libraries (79.65-87.30\% mapped rate, and 77.66-85.09\% unique mapped rate) and 49.5659.40 million for the X100 libraries (77.83-84.46\% mapped rate, and $75.66-82.18 \%$ unique mapped rate) (Additional file 2: Table S2).

\section{Genes that are differentially expressed in the root samples of Zea mays in response to graphene treatment}

We firstly calculated the Pearson correlation coefficient (PCC) of all the genes, and generated a heatmap plot showing changes in gene expression (as shown in Fig. 4A). The correlation coefficients of the three biological replicates were greater than 0.90 , indicating that the RNA-seq data were reliable for further analysis. Based on principal component analysis of six samples, the transcriptional response observed in Zea mays roots exposed to $50.00 \mathrm{mg} / \mathrm{L}$ graphene was due to the graphene treatment, and varieties with graphene treatment exhibited two levels of gene expression (as shown in Fig. 4B).

We were particularly interested in identifying transcripts that were differentially expressed in the root sample in response to graphene treatment, as such transcripts may represent genes related to root development under graphene treatment. The expression value of each gene was calculated using FPKM (Fragments Per Kilobase of transcript per Million fragments mapped) algorithm. A two-fold change and a $p$-value of less than 0.05 were set as the cutoffs to define genes with significant differential expression (Fig. 4C). We identified 962 differentially expressed genes, among which 792 were graphene-induced and 170 were graphene-repressed (Fig. 4D).

\section{Gene Enrichment Analysis For Differentially Expressed Genes}

To investigate possible biological functions that determine the different responses of the maize plants to $50.00 \mathrm{mg} / \mathrm{L}$ graphene treatment, we used GOseq [37] to perform GO category enrichment analysis for differentially expressed genes. Figure 5 lists the results of the gene ontology (GO) analysis for differentially expressed genes after graphene treatment. GO terms associated with important biological processes, such as the cellular, metabolic, developmental, and immune system processes, biological regulation, response to stimulus and detoxification were enriched in maize exposed to graphene treatment. GO terms associated with important cellular component, such as cell, membrane and organelle parts were enriched. GO terms associated with important molecular function, such as catalytic activity, transporter activity, nucleic acid binding transcription factor activity, antioxidant activity and transcription factor activity were enriched. 
DEGs were subjected to COG database [38] to classify the gene function and homology. Additional file 3: Figure $\mathrm{S} 1$ lists the results of the COG analysis for differentially expressed genes. Most DEGs were distributed on the orthologous groups of 1) secondary metabolites biosynthesis, transport and catabolism, 2) carbohydrate transport and metabolism, 3) amino acid transport and metabolism, 4) lipid transport and metabolism and 5) defense mechanisms.

DEGs were subjected to KEGG pathway analysis to identify the functional categorization. Additional file 4: Figure S2 lists the results of the KEGG analysis for differentially expressed genes. Most DEGs were categorized on the functional pathways of 1) metabolisms, including phenylpropanoid biosynthesis, glutathione metabolism, flavonoid biosynthesis, carbon metabolism, amino sugar and nucleotide sugar metabolism, cysteine and methionine metabolism, terpenoid backbone biosynthesis, biosynthesis of amino acids, as well as starch and sucrose metabolism etc; 2) cellular process of peroxisome; 3 ) environmental information processing, including plant hormone signal transduction, $A B C$ transporters, phosphatidylinositol signaling system, circadian rhythm in plant and plant-pathogen interaction. DEGs with up-regulation were assigned to 73 KEGG pathways, including phenylpropanoid biosynthesis, glutathione metabolism, flavonoid biosynthesis, and nitrogen metabolism (Fig. 6A). DEGs with downregulation were significantly enriched in 14 KEGG pathways, including amino sugar and nucleotide sugar metabolism, starch and sucrose metabolism pathways as well as plant hormone signal transduction (Fig. 6B) etc,. The results revealed that graphene could affect the expression of maize root genes, showing majority of up-regulation genes. The enrichment analysis illustrated that graphene treatment had extensive and distinct effects on the life processes in maize.

\section{Transcription Factors Enriched In Maize Plants Exposed To Graphene}

We found that the GO term "transcription factor activity, protein binding" was significantly enriched in maize roots subjected to graphene treatment (Fig. 5). Transcription factors are DNA-binding proteins that play a key role in gene transcription and expression that mediated many processes. Many transcription factors in the roots of maize responded to the graphene treatment, and the responses differed by up or down regulated expressions (Table 1). 44 maize transcription factor genes classified into 7 different families according to PlantTFDB [39], were differentially expressed under the graphene treatment, including ERF, WRKY, bHLH, MYB and MYB-like, NAC, AP2 as well as MADS-box. Among them, 32 transcription factor genes were up-regulated and 12 were down-regulated. The transcription factor genes activated in $Z$. mays roots in response to the graphene treatment mostly belonged to the MYB and MYBlike, WRKY, NAC and bHLH families, suggesting that these transcription factor genes might response to the graphene specifically in $Z$. mays root.

Many studies have proved that plant root development could be regulated by ERF [40], WRKY [41, 42], bHLH [43-45], MYB and MYB-like [46-49], NAC [50, 51], AP2 [52, 53] as well as MADS-box [54, 55] TF genes. After exposure to graphene treatment of $Z$. mays roots, there were three up and one down- 
regulated ethylene-responsive (ERF) transcription factor genes (Fig. 7A), eight up and one down-regulated WRKY TF genes (Fig. 7B), five up and one down-regulated bHLH TF genes (Fig. 7C), ten up and two downregulated MYB and MYB-like TF genes (Fig. 7D), three up and four down-regulated NAC TF genes (Fig. 7E), three up and one down-regulated AP2 TF genes (Fig. 7F) as well as two down-regulated MADSbox TF genes (Fig. 7G). As proved above, the total root length, root volume, the number of root tips and root forks (Fig. 3) of maize seedlings were increased after $50 \mathrm{mg} / \mathrm{L}$ graphene treatment. These improved root phenotypes might be affected by these differentially expressed transcription factor genes. Therefore, these TFs were considered the candidate graphene-responsive genes, and might be the internal causes in promoting the development of roots in Z. mays.

\section{Plant Hormone Signaling Pathways}

Plant hormones, including auxin, cytokinin (CK), gibberellin (GA), abscisic acid (ABA), ethylene, brassinosteroid (BR), jasmonate (JA), salicylic acid (SA), and strigolactone (SL) play critical roles in the plant's processes of growth, development and adapting to the external changing environments [56-59]. We identified differentially expressed genes related to nine hormone signal transduction pathways. An overview of gene expression patterns under graphene treatment in maize roots is shown in Fig. 8. Four auxin-responsive genes, such as gene-LOC100281448 (IAA9), gene-LOC103642166 (auxin response factor 11) and gene-PIN5c (auxin efflux carrier PIN5c) were differentially expressed in maize under graphene conditions, indicating the existence of crosstalk between graphene and auxin signaling. Therefore, auxin modulates the plant's response to graphene by altering the expression of genes involved in root growth regulation.

The cytokinin (CK) signaling pathway plays an important role in the plant's growth regulation. Four genes associated with the cytokinin signaling pathway showed significantly differentially expression under graphene treatment (Fig. 8). The expression of gene-cko1 (cytokinin oxidase1), gene-LOC100280143 (cytokinin-N-glucosyltransferase 1) and gene-LOC100282611 (cytokinin-O-glucosyltransferase 2) was increased. We found that five genes associated with the GA pathway were also up-regulated expressed, including gene-LOC100283080 (Gibberellin 20 oxidase 2), gene-LOC100283652 (gibberellin receptor GID1L2) and gene-gar1 (gibberellin responsive 1). JA and SA play important roles in plant defense response. The expression of six JA-related genes, such as gene-LOC100283794 (Jasmonate-induced protein), gene-LOC103629478 (jasmonate O-methyltransferase) and gene-LOC100273620 (Jasmonateregulated gene 21), and one SA-related gene (salicylic acid-binding protein 2) were up-regulated in the roots of maize subjected to graphene. Two gene involved in brassinosteroid (BR) and strigolactone (SL) signal transduction respectively were induced in response to graphene, suggesting the roles of grapheneresponsive hormones are emerging to function. Together, these results demonstrated that hormones might form a complex regulatory network related to the graphene response in roots.

\section{Nitrogen And Potassium Metabolism}


We also identified eight nitrogen and potassium metabolism genes that were differentially expressed (Fig. 9). All the five nitrogen metabolism genes were up-regulated (Fig. 9A) and three of them (gene-GLN6, gene-nrt2 and gene-nrt2.2) were validated by qRT-PCR analysis (Fig. 9B). These genes were annotated into the glutamine synthetase root isozyme 1 and nitrate transporter, which were involved in the nitrogen transmembrane transport and root development. In view of this, we measured the $\mathrm{N}$ content in the soil around the maize seedling roots, and the $\mathrm{N}$ content in $50.00 \mathrm{mg} / \mathrm{L}$ graphene was significantly increased, up to 1.64 times (Fig. 9C).

In addition, the expressions of three potassium metabolism genes (gene-HAK20, gene-HAK21 and genekup1) were up-regulated by RNA-seq (Fig. 9D) and qRT-PCR data (Fig. 9E). These genes were involved in the potassium ion transmembrane transport and uptake. We also measured the $\mathrm{K}$ content in the soil around the maize seedling roots, and the $\mathrm{K}$ content in $50.00 \mathrm{mg} / \mathrm{L}$ graphene was increased by 1.33 times (Fig. 9F). The results indicated that the soil fertility, such as the content of $\mathrm{N}$ and $\mathrm{K}$, could be elevated after irrigating the graphene, which further promote the growth and development of maize seedling roots.

\section{Qrt-pcr Identification Of Degs In Response To Graphene}

Furthermore, to validate the RNA-seq results, 20 DEGs were screened for qRT-PCR validation, including 14 transcription factor genes, three nitrogen metabolism and three potassium metabolism genes. We analyzed the expression of these genes using quantitative real-time PCR (qRT-PCR) analysis and compared the results with the RNA-seq data (Table 2). These transcripts had similar expression patterns in the qRT-PCR and RNA-seq experiments and the correlation coefficient between the two sets of data was 0.7783 (Table 2).

\section{Discussion}

Recently, the carbon nanomaterials researches had been focused on the applications in agriculture and forestry $[6,12,60-62]$. Studies have shown that graphene carbon nanotubes could affect the growth of maize root, promote the growth of seminal root, and had no effect on the growth of primary root, but will restrain the growth of root hair [60]. Liu et al. [12] proved that graphene could promote rice seed germination, affect root development and other physiological indicators. Graphene could interact with plants through root irrigation or leaf spraying. Graphene-induced of plant growth occurs in low concentrations but showed inhibition effects on plant growth in high concentrations. However, the mechanism of graphene's interaction with plants has not been thoroughly elucidated. In this study, we studied the transcriptomic responses of maize roots after the exposure to the $50 \mathrm{mg} / \mathrm{L}$ low concentration graphene solution.

\section{Identification of candidate graphene-related genes in $Z$. mays}


Using the RNA-seq technology, we successfully identified 962 differentially expressed genes in the roots of Zea mays subjected to graphene treatment. After exposure to graphene, the number of up-regulated DEGs was more than the down-regulated. Using GO and KEGG pathway analysis, we designed a transcriptome map of the maize seedling roots exposed to graphene. GO analysis showed that the GO terms "transporter activity", "transcription factor activity" as well as "response to stimulus and detoxification" were significantly enriched. KEGG pathway analysis indicated that DEGs of graphene treatment were involved in metabolisms and plant hormone signal transduction. Therefore, the maize root may has specific mechanism to respond graphene effect, such as the transcription factors, detoxification, metabolism, and hormone signals.

\section{Graphene-related transcription factor genes inZ. mays}

Plant responses to graphene may be related to the transcription factor genes. For example, several WRKY genes were significantly induced by graphene in the roots of maize. WRKY transcription factors are one of the largest families of transcriptional regulators in plants and WRKY proteins often act as activators or repressors to modulate important plant processes [63]. Li et al., [41] showed that WRKY genes were involved in the root elongation in Arabidopsis Hypoxia. Wang et al., [42] reported a WRKY transcription factor gene that could affect adventitious root formation in Catalpa Scop.

MYB and MYB-like TF families are involved in controlling trichomes development and root hair formation [46-49]. In addition, the R2R3 MYBs, the basic helix-loop-helix (bHLH) factors, and the WD40 repeat (WDR) protein, plays a crucial role in trichome development. These three groups of TFs form a trimeric activator complex, MYB-bHLH-WDR (MBW) that positively regulates the expression of downstream targets, which, in turn, induces trichome formation [64].

Studies also showed that bHLH transcription factor genes were involved in the root hair and meristem development in plants [43-45], and NAC transcription factor genes regulated lateral root development in potato [50] and enhances root length in wheat [51]. In our study, we identified some differentially expressed WRKY, MYB and MYB-like, bHLH as well as NAC transcription factor genes in response to the graphene treatment. It is possible to speculate that graphene could stimulate maize root growth by upregulating these transcription factor gene expressions.

\section{A potential graphene response regulatory network inZ. mays}

Based on our analysis, we propose a model for the mechanism underlying graphene effect on the root growth of maize (Fig. 10). When the roots of maize seedlings grown in soil are exposed to gaphene, the $\mathrm{N}$ and $\mathrm{K}$ contents of soil would be elevated because of the cation- $\pi$ interactions in graphene, which lead to the accumulation of cations on the graphene surface [65]. Thus, the transporters in the root (such as Nitrate transporter, nrt2.2; potassium transporter 5, HAK20) may recognize the corresponding signals and trigger the expression increase of transporter genes, and the change of phytohormones, including auxin, 
cytokinin and gibberellin, and so on. These hormones might affect the downstream transcription factors, such as WRKY, MYB, bHLH and NAC, which regulate the expression of target genes at the transcriptional level to promote the root elongation or hair growth. The graphene responses also involve detoxification and carbohydrate metabolism.

\section{Conclusions}

In this study, six low concentrations graphene were used to irrigate maize seedling roots to identify the optimal working solution in promoting the growth and development of Zea mays. Then, we used RNA-seq analysis to generate a transcription map of genes expressed in the roots of Zea mays in response to graphene treatment. Our results presented important insights into the molecular mechanisms that govern the response of Zea mays to graphene. The genes that were differentially expressed in maize root after graphene treatment are potential candidates for better utilize the graphene from the perspective of molecular biology. These results laid a theoretical foundation for the subsequent research on the molecular mechanism of the interaction between graphene and maize roots.

\section{Methods}

\section{Graphene characterization}

Graphene was obtained and generated from our own lab. The characteristics of graphene were analyzed by ultraviolet-visible absorption spectrogram and Raman spectroscopy (HORIBA, LabRAM HR Evolution). Raman spectra were obtained using Renishaw inVia ${ }^{\mathrm{TM}}$ Qontor with a $532 \mathrm{~nm}$ excitation laser. The morphology of graphene was examined using scanning electron microscopy (SEM, TESCAN MAIA 3 LMH) and transmission electron microscopy (TEM, TecnaiG2F20 S-TWIN TMP).

\section{Maize plants cultivation and graphene exposure treatment}

Maize seeds with the identical size divided into six groups (30 seeds in each group) were germinated in potting soil in a growth chamber, and the resulting seedlings were maintained in a controlled environment at $28^{\circ} \mathrm{C}$ day $/ 20^{\circ} \mathrm{C}$ night, with a 16 -h light/8-h dark photoperiod. Graphene working solutions $(0,20,25$, 33,50 and $100 \mathrm{mg} / \mathrm{L}$ ) was diluted to terminal concentrations with deionized water. An aqueous solution of sodium hydroxide $(0.1 \mathrm{M})$ was used to neutralize the working solutions to $\mathrm{pH} 6.3-6.5$. Maize seeds and seedlings were irrigated with six graphene solution concentrations, respectively. The graphene working solutions were irrigated once a week from the beginning of sowing job. After germination, the maize seedlings cultivated in soil pots were watered with $1 \mathrm{~L}$ working solution with different concentrations of graphene per week. For the blank group, the irrigation solution was the same amount of distilled water, and the other treatments were consistent with the experimental group. After 30 days of exposure to graphene, the maize roots were thoroughly washed with deionized water, dried with 
absorbent paper to remove the surface water, following promptly frozen in liquid nitrogen and stored at $-80^{\circ} \mathrm{C}$ for RNA extraction.

\section{Root Architecture Analysis Of Maize Seedlings}

The maize seedlings treated with six graphene concentrations were used for root architecture analysis. After 30 days of exposure to graphene, the maize roots were thoroughly washed with deionized water, then the roots were scanned using Epson Perfection V850 Pro (Seiko Epson Corp., Tokyo, Japan) at 600 dpi. Then scanned images were quantized by WinRHIZO (Version 4.0b, Regent Instruments Inc., Quebec, Canada) [66]. Root architecture, including total root length, total project area, total surface area, root volume, the number of root tips and root forks were measured.

\section{Rna Extraction, Libraries Construction And Sequencing}

Total RNA of maize roots from the control and $50 \mathrm{mg} / \mathrm{L}$ graphene treatment groups were isolated. A total of $1 \mu \mathrm{g}$ purified mRNA was selected for cDNA library construction using NEBNext UltraTM RNA Library Prep Kit for Illumina (NEB, USA), following the manufacturer protocol. Briefly, mRNA was purified from total RNA using poly-T oligo-attached magnetic beads. Fragmentation was carried out using divalent cations under elevated temperature in NEBNext First Strand Synthesis Reaction Buffer (5X). First strand cDNA was synthesized using random hexamer primer and M-MuLV Reverse Transcriptase. Second strand cDNA synthesis was subsequently performed using DNA Polymerase I and RNase H. Remaining overhangs were converted into blunt ends via exonuclease/polymerase activities. After adenylation of 3' ends of DNA fragments, NEBNext Adaptor with hairpin loop structure were ligated to prepare for the hybridization. In order to select CDNA fragments of preferentially $300 \mathrm{bp}$ in length, the library fragments were purified with AMPure XP system (Beckman Coulter, Beverly, USA). Then $3 \mu$ I USER Enzyme (NEB, USA) was used with size-selected, adaptor-ligated cDNA at $37^{\circ} \mathrm{C}$ for $15 \mathrm{~min}$ followed by 5 min at $95^{\circ} \mathrm{C}$ before PCR. Then PCR was performed with Phusion High-Fidelity DNA polymerase, Universal PCR primers and Index (X) Primer. At last, PCR products were purified (AMPure XP system) and library quality was assessed on the Agilent Bioanalyzer 2100 system. The clustering of the index-coded samples was performed on a cBot Cluster Generation System using TruSeq PE Cluster Kit v4-cBot-HS (Illumia) according to the manufacturer's instructions. After cluster generation, the library preparations were sequenced on an Illumina novaseq platform and $150 \mathrm{bp}$ paired-end reads were generated. Three biological replicates were performed for both CK and graphene treatment groups.

\section{Rna-seq Data Quality Control And Reads Mapping}

Raw data (raw reads) of fastq format were firstly processed through FASTX-Toolkit (http://hannonlab.cshl.edu/fastx_toolkit/). In this step, clean data (clean reads) were obtained by removing reads containing adapter, reads containing ploy- $\mathrm{N}$ and low quality reads from raw data. At the 
same time, Q20, Q30, GC-content and sequence duplication level of the clean data were calculated. All the downstream analyses were based on the clean data with high quality. These clean reads were then mapped to the Zea mays (assembly B73 RefGen_v4) reference genome [67] sequences using HISAT2 software $[68,69]$. Only reads with perfect match or one mismatch were further analyzed to calculate the expression values. The clean data were deposited in the Genome Sequence Archive in the BIG Data Center of Sciences under accession code CRA002623.

\section{Quantification of gene expression levels and differentially expressed gene analysis}

Gene expression levels were calculated by fragments per kilobase of transcript per million fragments mapped. The formula is shown as follow:

FPKM $=\{c D N A$ Fragments \over $\{$ Mapped Fragments(Millions) *Transcript Length(kb)\}\}.

Differential expression analysis of two groups was performed using the DESeq2 [70]. DESeq2 provide statistical routines for determining differential expression in digital gene expression data using a model based on the negative binomial distribution. The resulting $p$ values were adjusted using the Benjamini and Hochberg's approach for controlling the false discovery rate (FDR). Genes with an adjusted $p$-value < 0.01 and two-fold up and down change identified by DESeq2 [70] were assigned as differentially expressed. Multiple Experiment Viewer (MeV) [71] was used to display the gene expression patterns from the FPKM values.

\section{Differentially Expressed Gene Functional Annotation And Enrichment Analyses}

Differentially expressed gene functions were annotated based on the following databases: $\mathrm{Nr}$ (NCBI nonredundant protein sequences, ftp://ftp.ncbi.nih.gov/blast/db/), Nt (NCBI non-redundant nucleotide sequences, ftp://ftp.ncbi.nih.gov/blast/db/), Pfam (The database of Homologous protein family, http://pfam.xfam.org/), COG (Clusters of Orthologous Groups of proteins, http://www.ncbi.nlm.nih.gov/COG/), Swiss-Prot (A manually annotated and reviewed protein sequence database, http://www.uniprot.org/), KO (KEGG Ortholog database, http://www.genome.jp/kegg/), as well as GO (Gene Ontology, http://www.geneontology.org/).

Gene Ontology (GO) enrichment analysis of the differentially expressed genes (DEGs) was implemented by the GOseq R packages based Wallenius non-central hyper-geometric distribution [37], which can adjust for gene length bias of DEGs. We used KOBAS [72] software to test the statistical enrichment of differential expression genes in KEGG pathways. 


\section{Rna Extraction, Cdna Synthesis And Qrt-pcr Validation}

Total RNAs of maize roots from the control and $50.00 \mathrm{mg} / \mathrm{L}$ graphene treatment groups were extracted using the RNAprep pure plant kit (TIANGEN, Shanghai, China) according to the manufacturer's protocol. The resulting RNAs were treated with DNase I prior to synthesizing cDNA with oligo (dT) primers and MMLV Reverse Transcriptase (Invitrogen); these products were diluted 5-fold before use. For quantitative real-time PCR (qRT-PCR), Primer5 software was used to design gene-specific forward and reverse primers (Additional file 5: Table S3). Analyses were performed with SYBR-Green PCR Mastermix (TaKaRa) on a cycler (Mastercycler RealPlex; Eppendorf Ltd, Shanghai, China). The Zea mays GAPDH (ZmGAPDH) gene was used as the internal reference, and the relative amount of the amplified product was calculated following the 2- $\Delta \Delta \mathrm{Ct}$ method [73]. The relative expression levels were normalized by calibrating with the CK sample from roots. The root sample was washed by the DEPC sterile water three times before extracting the RNA.

\section{Measurement of $\mathrm{N}$ and $\mathrm{K}$ contents in soil around the maize root system}

Soil nutrient analyzer was used to determine the contents of $\mathrm{N}$ and $\mathrm{K}$ around the root system of maize seedlings in the soil according to the manufacturer's protocol. The soil around the root system was sampled with the 5-point sampling method. The soil samples were thoroughly mixed and dried for 24 hours. After being sifted with a $1 \mathrm{~mm}$ sieve, the soil samples were used for further measurement, respectively.

\section{Statistical analysis}

Each treatment was conducted in triplicate, and the results are presented as the means \pm standard deviation (SD). The data were analyzed using one-way analysis of variance (ANOVA). Significance of difference between means was determined by least significant difference (LSD) at the 0.05 probability level. Pairwise comparisons were used by Student's $t$ test and differences were regarded as significant at $p<0.05$. All statistical analyses were performed using SPSS 21 (Predictive Analytics Software statistics 21).

\section{List Of Abbreviations}

DEGs: Differentially expressed genes; GO: Gene ontology; COG: Clusters of Orthologous Groups; FPKM: Fragments per kilobase of transcript per million mapped fragments; Z. mays: Zea mays; qRT-PCR: Quantitative real-time polymerase chain reaction

\section{Declarations}




\section{Ethics approval and consent to participate}

Not applicable

\section{Consent for publication}

Not applicable

\section{Compliance and ethics}

The authors declare that they have no competing interests.

\section{Availability of data and materials}

All the data generated or analyzed during this study are included in this published article and its Additional files. The clean data were deposited in the Genome Sequence Archive in the BIG Data Center of Sciences under accession code CRA002623.

\section{Competing interests}

The authors declare that they have no competing interests

\section{Funding}

This work reported in this publication was supported by the Shanxi graphene industrialization application technology of collaborative innovation center, Shanxi graphene functional materials engineering technology research center (201705D141034), Shanxi New Carbon Functional Materials Engineering Research Center, Special talents in Shanxi Province (talents science and technology innovation》 (201705D211010), Datong applied basic research (2017123), Science and Technology Achievements Transformation Guide project of Shanxi province (201804D131041).

\section{Authors' contributions}

ZWC and JGZ conceived the project; ZWC and ZHL performed the experiment. ZWC, JS, SHH, YQD, YYQ, JQ, WJL, JWL, and HYW analyzed the data; BYX and QLP performed the SEM and TEM, Raman spectra analysis. ZWC and JGZ wrote and revised the manuscript. All authors have read and approved the manuscript.

\section{References}

1. Liu XH, Wang JW, Huang S, Fan F, Huang X, Liu Y, Krylyuk S, Yoo J, Dayeh SA, Davydov AV et al: In situ atomic-scale imaging of electrochemical lithiation in silicon. Nature nanotechnology 2012, 7(11):749-756. 
2. Shi W, Fredrickson GH, Kramer EJ, Ntaras C, Avgeropoulos A, Demassieux Q, Creton C: Mechanics of an Asymmetric Hard-Soft Lamellar Nanomaterial. ACS nano 2016, 10(2):2054-2062.

3. Pang H, Ma Y, Li G, Chen J, Zhang J, Zheng H, Du W: Facile synthesis of porous ZnO-NiO composite micropolyhedrons and their application for high power supercapacitor electrode materials. Dalton transactions 2012, 41(43):13284-13291.

4. Valentini F, Carbone M, Palleschi G: Carbon nanostructured materials for applications in nanomedicine, cultural heritage, and electrochemical biosensors. Analytical and bioanalytical chemistry 2013, 405(2-3):451-465.

5. Zuverza-Mena N, Martinez-Fernandez D, Du W, Hernandez-Viezcas JA, Bonilla-Bird N, Lopez-Moreno ML, Komarek M, Peralta-Videa JR, Gardea-Torresdey JL: Exposure of engineered nanomaterials to plants: Insights into the physiological and biochemical responses-A review. Plant Physiol Biochem 2017, 110:236-264.

6. Canas JE, Long M, Nations S, Vadan R, Dai L, Luo M, Ambikapathi R, Lee EH, Olszyk D: Effects of functionalized and nonfunctionalized single-walled carbon nanotubes on root elongation of select crop species. Environmental toxicology and chemistry 2008, 27(9):1922-1931.

7. Avouris P: Graphene: electronic and photonic properties and devices. Nano Lett 2010, 10(11):42854294.

8. De Jesus LR, Dennis RV, Depner SW, Jaye C, Fischer DA, Banerjee S: Inside and outside: X-ray absorption spectroscopy mapping of chemical domains in graphene oxide. J Phys Chem Lett 2010, 4(18):3144-3151.

9. Zhang M, Gao B, Chen J, Li Y: Effects of graphene on seed germination and seedling growth. Journal of Nanoparticle Research 2015, 17(2):78.

10. He Y, Hu R, Zhong Y, Zhao X, Chen Q, Zhu H: Graphene oxide as a water transporter promoting germination of plants in soil. Nano Research 2018, 11(4):1928-1937.

11. Hu X, Zhou Q: Novel hydrated graphene ribbon unexpectedly promotes aged seed germination and root differentiation. Sci Rep 2014, 4:3782.

12. Liu S, Wei H, Li Z, Li S, Yan H, He Y, Tian Z: Effects of Graphene on Germination and Seedling Morphology in Rice. Journal of nanoscience and nanotechnology 2015, 15(4):2695-2701.

13. Chakravarty D, Erande MB, Late DJ: Graphene quantum dots as enhanced plant growth regulators: effects on coriander and garlic plants. J Sci Food Agr 2015, 95(13):2772-2778.

14. Anjum NA, Singh N, Singh MK, Shah ZA, Duarte AC, Pereira E, Ahmad I: Single-bilayer graphene oxide sheet tolerance and glutathione redox system significance assessment in faba bean (Vicia faba L.). Journal of Nanoparticle Research 2013, 15(7):1770.

15. Ren W, Chang H, Teng Y: Sulfonated graphene-induced hormesis is mediated through oxidative stress in the roots of maize seedlings. Sci Total Environ 2016, 572:926-934.

16. Pandey K, Anas M, Hicks V, Green M, Khodakovskaya M: Improvement of commercially valuable traits of industrial crops by application of carbon-based nanomaterials. Sci Rep 2019, 9:19358. 
17. Zhang M, Gao B, Chen J, Li Y, Creamer AE, Chen H: Slow-release fertilizer encapsulated by graphene oxide films. Chem Eng J 2014, 255:107-113.

18. Andelkovic IB, Kabiri S, Tavakkoli E, Kirby JK, McLaughlin MJ, Losic D: Graphene oxide-Fe(III) composite containing phosphate - A novel slow release fertilizer for improved agriculture management. J Clean Prod 2018, 185:97-104.

19. Kabiri S, Degryse F, Tran DNH, da Silva RC, McLaughlin MJ, Losic D: Graphene oxide: A new carrier for slow release of plant micronutrients. ACS Appl Mater Inter 2017, 9(49):43325-43335.

20. He Y, Qian L, Liu X, Hu R, Huang M, Liu Y, Chen G, Losic D, Zhu H: Graphene oxide as an antimicrobial agent can extend the vase life of cut flowers.

21. Wang X, Liu C, Li H, Zhang H, Ma R, Zhang Q, Yang F, Liao Y-c, Yuan W, Chen F: Metabonomicsassisted label-free quantitative proteomic and transcriptomic analysis reveals novel insights into the antifungal effect of graphene oxide for controlling Fusarium graminearum. Environmental Science: Nano 2019, 6(11):3401-3421.

22. Wang Q, Li C, Wang Y, Que X: Phytotoxicity of graphene family nanomaterials and its mechanisms: a review. Front Chem 2019, 7(292):00292.

23. Efremova LV, Vasilchenko AS, Rakov EG, Deryabin DG: Toxicity of Graphene Shells, Graphene Oxide, and Graphene Oxide Paper Evaluated with Escherichia coli Biotests. Biomed Res Int 2015, 2015:869361.

24. Begum P, Ikhtiari R, Fugetsu B: Graphene phytotoxicity in the seedling stage of cabbage, tomato, red spinach, and lettuce. Carbon 2011, 49(12):3907-3919.

25. Du S, Zhang P, Zhang R, Lu Q, Liu L, Bao X, Liu H: Reduced graphene oxide induces cytotoxicity and inhibits photosynthetic performance of the green alga Scenedesmus obliquus. Chemosphere 2016, 164:499-507.

26. Begum $P$, Fugetsu B: Induction of cell death by graphene in Arabidopsis thaliana (Columbia ecotype) T87 cell suspensions. J Hazard Mater 2013, 260:1032-1041.

27. Zhao S, Wang Q, Zhao Y, Rui Q, Wang D: Toxicity and translocation of graphene oxide in Arabidopsis thaliana. Environ Toxicol Pharmacol 2015, 39(1):145-156.

28. Gao M, Yang Y, Song Z: Effects of graphene oxide on cadmium uptake and photosynthesis performance in wheat seedlings. Ecotoxicol Environ Saf 2019, 173:165-173.

29. Zhang P, Zhang R, Fang X, Song T, Cai X, Liu H, Du S: Toxic effects of graphene on the growth and nutritional levels of wheat (Triticum aestivum L.): short- and long-term exposure studies. $J$ Hazard Mater 2016, 317:543-551.

30. He Y, Qian L, Zhou K, Hu R, Huang M, Wang M, Zhao G, Liu Y, Xu Z, Zhu H: Graphene oxide promoted cadmium uptake by rice in soil. ACS sustainable chemistry \& engineering 2019, 2019 v.7 no.12(no. 12):pp. 10283-10292.

31. Zhang P, Guo Z, Luo W, Monikh FA, Xie C, Valsami-Jones E, Lynch I, Zhang Z: Graphene oxide-induced $\mathrm{pH}$ alteration, iron overload, and subsequent oxidative damage in rice (Oryza sativa L.): A new 
mechanism of nanomaterial phytotoxicity. Environmental science \& technology 2020, 54(6):31813190.

32. Li F, Sun C, Li X, Yu X, Luo C, Shen Y, Qu S: The effect of graphene oxide on adventitious root formation and growth in apple. Plant Physiol Biochem 2018, 129:122-129.

33. Huang C, Xia T, Niu J, Yang Y, Lin S, Wang X, Yang G, Mao L, Xing B: Transformation of (14) C-labeled graphene to (14) $\mathrm{CO}_{2}$ in the shoots of a rice plant. Angewandte Chemie 2018, 57(31):9759-9763.

34. Kudin KN, Ozbas B, Schniepp HC, Prud'homme RK, Aksay IA, Car R: Raman spectra of graphite oxide and functionalized graphene sheets. Nano letters 2008, 8(1):36-41.

35. Ferrari AC, Meyer JC, Scardaci V, Casiraghi C, Lazzeri M, Mauri F, Piscanec S, Jiang D, Novoselov KS, Roth S et al: Raman spectrum of graphene and graphene layers. Phys Rev Lett 2006, 97(18):187401.

36. Schnable PS, Ware D, Fulton RS, Stein JC, Wei F, Pasternak S, Liang C, Zhang J, Fulton L, Graves TA et al: The B73 maize genome: complexity, diversity, and dynamics. Science 2009, 326(5956):11121115.

37. Young MD, Wakefield MJ, Smyth GK, Oshlack A: Gene ontology analysis for RNA-seq: accounting for selection bias. Genome Biol 2010, 11(2):R14.

38. Tatusov RL, Fedorova ND, Jackson JD, Jacobs AR, Kiryutin B, Koonin EV, Krylov DM, Mazumder R, Mekhedov SL, Nikolskaya AN et al: The COG database: an updated version includes eukaryotes. BmC Bioinformatics 2003, 4:41.

39. Jin J, Tian F, Yang DC, Meng YQ, Kong L, Luo J, Gao G: PlantTFDB 4.0: toward a central hub for transcription factors and regulatory interactions in plants. Nucleic Acids Res 2017, 45(D1):D1040D1045.

40. Kitomi $\mathrm{Y}$, Ito $\mathrm{H}$, Hobo $\mathrm{T}$, Aya $\mathrm{K}$, Kitano $\mathrm{H}$, Inukai $\mathrm{Y}$ : The auxin responsive AP2/ERF transcription factor CROWN ROOTLESS5 is involved in crown root initiation in rice through the induction of OsRR1, a type-A response regulator of cytokinin signaling. Plant J 2011, 67(3):472-484.

41. Li S, Nayar S, Jia H, Kapoor S, Wu J, Yukawa Y: The Arabidopsis Hypoxia inducible AtR8 long noncoding RNA also contributes to plant defense and root elongation coordinating with WRKY genes under low levels of salicylic acid. Non-coding RNA 2020, 6(1).

42. Wang P, Ma L, Wang S, Li L, Wang Q, Yang R, Li Y: Identification and analysis of a candidate WRKY transcription factor gene affecting adventitious root formation using association mapping in Catalpa Scop. DNA and cell biology 2019, 38(4):297-306.

43. Makkena S, Lamb RS: The bHLH transcription factor SPATULA regulates root growth by controlling the size of the root meristem. Bmc Plant Bio/2013, 13:1.

44. Gajewska P, Janiak A, Kwasniewski M, Kedziorski P, Szarejko I: Forward genetics approach reveals a mutation in bHLH transcription factorencoding gene as the best candidate for the root hairless phenotype in Barley. Front Plant Sci 2018, 9:1229.

45. Ding W, Yu Z, Tong Y, Huang W, Chen H, Wu P: A transcription factor with a bHLH domain regulates root hair development in rice. Cell Res 2009, 19(11):1309-1311. 
46. Wang S, Wang JW, Yu N, Li CH, Luo B, Gou JY, Wang LJ, Chen XY: Control of plant trichome development by a cotton fiber MYB gene. Plant Cell 2004, 16(9):2323-2334.

47. Machado A, Wu Y, Yang Y, Llewellyn DJ, Dennis ES: The MYB transcription factor GhMYB25 regulates early fibre and trichome development. Plant J 2009, 59(1):52-62.

48. Zheng K, Tian H, Hu Q, Guo H, Yang L, Cai L, Wang X, Liu B, Wang S: Ectopic expression of R3 MYB transcription factor gene OsTCL1 in Arabidopsis, but not rice, affects trichome and root hair formation. Sci Rep 2016, 6:19254.

49. Tominaga-Wada R, Nukumizu Y, Sato S, Wada T: Control of plant trichome and root-hair development by a tomato (Solanum lycopersicum) R3 MYB transcription factor. PLoS One 2013, 8(1):e54019.

50. Zhang L, Yao L, Zhang N, Yang J, Zhu X, Tang X, Calderon-Urrea A, Si H: Lateral root development in potato is mediated by Stu-mi164 regulation of NAC transcription factor. Front Plant Sci 2018, 9:383.

51. Chen D, Chai S, McIntyre CL, Xue GP: Overexpression of a predominantly rootexpressed NAC transcription factor in wheat roots enhances root length, biomass and drought tolerance. Plant Cell Rep 2018, 37(2):225-237.

52. Nie J, Wen C, Xi L, Lv S, Zhao Q, Kou Y, Ma N, Zhao L, Zhou X: The AP2/ERF transcription factor CmERF053 of chrysanthemum positively regulates shoot branching, lateral root, and drought tolerance. Plant Cell Rep 2018, 37(7):1049-1060.

53. Trupiano D, Yordanov Y, Regan S, Meilan R, Tschaplinski T, Scippa GS, Busov V: Identification, characterization of an AP2/ERF transcription factor that promotes adventitious, lateral root formation in Populus. Planta 2013, 238(2):271-282.

54. Yu LH, Miao ZQ, Qi GF, Wu J, Cai XT, Mao JL, Xiang CB: MADS-box transcription factor AGL21 regulates lateral root development and responds to multiple external and physiological signals. $\mathrm{Mol}$ Plant 2014, 7(11):1653-1669.

55. Yu C, Liu Y, Zhang A, Su S, Yan A, Huang L, Ali I, Liu Y, Forde BG, Gan Y: MADS-box transcription factor OsMADS25 regulates root development through affection of nitrate accumulation in rice. PLoS One 2015, 10(8):e0135196.

56. Yang C, Liu J, Dong X, Cai Z, Tian W, Wang X: Short-term and continuing stresses differentially interplay with multiple hormones to regulate plant survival and growth. Mol Plant 2014, 7(5):841855.

57. Kang SM, Khan AL, Hamayun M, Hussain J, Joo GJ, You YH, Kim JG, Lee IJ: Gibberellin-producing Promicromonospora sp. SE188 improves Solanum lycopersicum plant growth and influences endogenous plant hormones. Journal of microbiology 2012, 50(6):902-909.

58. Islam W, Naveed H, Zaynab M, Huang Z, Chen HYH: Plant defense against virus diseases; growth hormones in highlights. Plant Signal Behav 2019, 14(6):1596719.

59. Ali S, Zhang Q: Overview of Sustainable Plant Growth and Differentiation and the Role of Hormones in Controlling Growth and Development of Plants under Various Stresses. Recent patents on food, nutrition \& agriculture 2019. 
60. Mukherjee A, Majumdar S, Servin AD, Pagano L, Dhankher OP, White JC: Carbon Nanomaterials in Agriculture: A Critical Review. Front Plant Sci 2016, 7:172.

61. Yan S, Zhao L, Li H, Zhang Q, Tan J, Huang M, He S, Li L: Single-walled carbon nanotubes selectively influence maize root tissue development accompanied by the change in the related gene expression. $J$ Hazard Mater 2013, 246-247:110-118.

62. Nair R, Mohamed MS, Gao W, Maekawa T, Yoshida Y, Ajayan PM, Kumar DS: Effect of carbon nanomaterials on the germination and growth of rice plants. Journal of nanoscience and nanotechnology 2012, 12(3):2212-2220.

63. Rushton PJ, Somssich IE, Ringler P, Shen QJ: WRKY transcription factors. Trends Plant Sci 2010, 15(5):247-258.

64. Pattanaik S, Patra B, Singh SK, Yuan L: An overview of the gene regulatory network controlling trichome development in the model plant, Arabidopsis. Front Plant Sci 2014, 5:259.

65. Zhao G, Zhu H: Cation-pi interactions in graphene-containing systems for water treatment and beyond. Advanced materials 2020:e1905756.

66. Pang W, Crow WT, Luc JE, McSorley R, Giblin-Davis RM, Kenworthy KE, Kruse JK: Comparison of Water Displacement and WinRHIZO Software for Plant Root Parameter Assessment. Plant Dis 2011, 95(10):1308-1310.

67. Jiao Y, Peluso P, Shi J, Liang T, Stitzer MC, Wang B, Campbell MS, Stein JC, Wei X, Chin CS et al: Improved maize reference genome with single-molecule technologies. Nature 2017, 546(7659):524527.

68. Kim D, Langmead B, Salzberg SL: HISAT: a fast spliced aligner with low memory requirements. Nat Methods 2015, 12(4):357-360.

69. Pertea M, Kim D, Pertea GM, Leek JT, Salzberg SL: Transcript-level expression analysis of RNA-seq experiments with HISAT, StringTie and Ballgown. Nat Protoc 2016, 11(9):1650-1667.

70. Love MI, Huber W, Anders S: Moderated estimation of fold change and dispersion for RNA-seq data with DESeq2. Genome Bio/ 2014, 15(12):550.

71. Saeed Al, Sharov V, White J, Li J, Liang W, Bhagabati N, Braisted J, Klapa M, Currier T, Thiagarajan M et al: TM4: a free, open-source system for microarray data management and analysis. BioTechniques 2003, 34(2):374-378.

72. Mao X, Cai T, Olyarchuk JG, Wei L: Automated genome annotation and pathway identification using the KEGG Orthology (KO) as a controlled vocabulary. Bioinformatics 2005, 21(19):3787-3793.

73. Livak KJ, Schmittgen TD: Analysis of relative gene expression data using real-time quantitative PCR and the 2(T)(-Delta Delta C) method. Methods 2001, 25(4):402-408.

\section{Tables}

Table 1 Differentially expressed transcription factor (TF) genes between CK and graphene treatment of root samples in Zea mays. 


\begin{tabular}{cccc}
\hline TF family & Gene Numbers & Up & Down \\
\hline ERF & 4 & 3 & 1 \\
WRKY & 9 & 8 & 1 \\
bHLH & 6 & 5 & 1 \\
MYB and MYB-like & 12 & 10 & 2 \\
NAC & 7 & 3 & 4 \\
AP2 & 4 & 3 & 1 \\
MADS-box & 2 & 0 & 2 \\
total & 44 & 32 & 12 \\
\hline
\end{tabular}

Table 2 qRT-PCR validation of the RNA-seq results.

\begin{tabular}{|c|c|c|c|c|c|c|}
\hline \multirow[t]{2}{*}{ Gene ID } & \multirow[t]{2}{*}{ Function annotations } & \multicolumn{2}{|c|}{ RNA-seq } & \multicolumn{2}{|c|}{ qRT-PCR } & \multirow[t]{2}{*}{ Regulation } \\
\hline & & $\begin{array}{l}\text { Fold } \\
\text { change }\end{array}$ & FDR & $\begin{array}{l}\text { Fold } \\
\text { change }\end{array}$ & $p$-value & \\
\hline gene-EREB60 & AP2-EREBP transcription factor & 2.74 & $\begin{array}{l}6.12 \mathrm{E}- \\
04\end{array}$ & 2.28 & $\begin{array}{l}2.16 \mathrm{E}- \\
03\end{array}$ & up \\
\hline gene-LOC541743 & Transcription factor MYB30 isoform X1 & 3.51 & $\begin{array}{l}4.87 \mathrm{E}- \\
03\end{array}$ & 5.58 & $\begin{array}{l}2.67 \mathrm{E}- \\
06\end{array}$ & up \\
\hline gene-MYB64 & Transcription repressor MYB6 & 2.48 & $\begin{array}{l}1.42 \mathrm{E}- \\
06\end{array}$ & 5.32 & $\begin{array}{l}3.12 \mathrm{E}- \\
03\end{array}$ & up \\
\hline gene-myb8 & Transcription factor MYB8 & 3.83 & $\begin{array}{l}5.45 \mathrm{E}- \\
12\end{array}$ & 6.26 & $\begin{array}{l}2.66 \mathrm{E}- \\
02\end{array}$ & up \\
\hline $\begin{array}{l}\text { gene- } \\
\text { LOC103651266 }\end{array}$ & WRKY transcription factor 51 & 3.74 & $\begin{array}{l}2.39 \mathrm{E}- \\
05\end{array}$ & 2.18 & $\begin{array}{l}1.89 \mathrm{E}- \\
03\end{array}$ & up \\
\hline gene-WRKY45 & $\begin{array}{l}\text { WRKY DNA-binding domain } \\
\text { superfamily protein }\end{array}$ & 0.37 & $\begin{array}{l}3.91 \mathrm{E}- \\
04\end{array}$ & 0.25 & $\begin{array}{l}3.06 \mathrm{E}- \\
04\end{array}$ & down \\
\hline $\begin{array}{l}\text { gene- } \\
\text { LOC103628959 }\end{array}$ & MADS-box transcription factor 26 & 0.30 & $\begin{array}{l}1.75 \mathrm{E}- \\
04\end{array}$ & 0.38 & $\begin{array}{l}8.46 \mathrm{E}- \\
02\end{array}$ & down \\
\hline gene-bHLH94 & $\begin{array}{l}\text { bHLH DNA-binding domain } \\
\text { superfamily protein }\end{array}$ & 2.33 & $\begin{array}{l}1.88 \mathrm{E}- \\
04\end{array}$ & 4.37 & $\begin{array}{l}4.56 \mathrm{E}- \\
03\end{array}$ & up \\
\hline $\begin{array}{l}\text { gene- } \\
\text { LOC103631852 }\end{array}$ & Transcription factor EMB1444 & 2.22 & $\begin{array}{l}4.93 \mathrm{E}- \\
04\end{array}$ & 3.89 & $\begin{array}{l}2.49 \mathrm{E}- \\
05\end{array}$ & up \\
\hline $\begin{array}{l}\text { gene- } \\
\text { LOC103633674 }\end{array}$ & NAC transcription factor 32 & 8.55 & $\begin{array}{l}2.85 \mathrm{E}- \\
04\end{array}$ & 6.26 & $\begin{array}{l}1.80 \mathrm{E}- \\
03\end{array}$ & up \\
\hline $\begin{array}{l}\text { gene- } \\
\text { LOC103653847 }\end{array}$ & NAC domain-containing protein 7 & 0.20 & $\begin{array}{l}6.75 \mathrm{E}- \\
03\end{array}$ & 0.13 & $\begin{array}{l}5.17 \mathrm{E}- \\
03\end{array}$ & down \\
\hline $\begin{array}{l}\text { gene- } \\
\text { LOC103625838 }\end{array}$ & Transcription factor JUNGBRUNNEN 1 & 2.46 & $\begin{array}{l}3.63 \mathrm{E}- \\
03\end{array}$ & 3.36 & $\begin{array}{l}4.39 \mathrm{E}- \\
02\end{array}$ & up \\
\hline $\begin{array}{l}\text { gene- } \\
\text { LOC103630375 }\end{array}$ & $\begin{array}{l}\text { Ethylene-responsive transcription } \\
\text { factor ERF020 }\end{array}$ & 0.36 & $\begin{array}{l}9.69 \mathrm{E}- \\
03\end{array}$ & 0.29 & $\begin{array}{l}3.68 \mathrm{E}- \\
05\end{array}$ & down \\
\hline $\begin{array}{l}\text { gene- } \\
\text { LOC103635988 }\end{array}$ & $\begin{array}{l}\text { Ethylene-responsive transcription } \\
\text { factor WRI1 }\end{array}$ & 2.86 & $\begin{array}{l}2.45 \mathrm{E}- \\
04\end{array}$ & 4.16 & $\begin{array}{l}6.44 \mathrm{E}- \\
03\end{array}$ & up \\
\hline gene-GLN6 & Glutamine synthetase root isozyme 1 & 2.88 & $\begin{array}{l}2.34 \mathrm{E}- \\
07\end{array}$ & 2.65 & $\begin{array}{l}3.32 \mathrm{E}- \\
02\end{array}$ & up \\
\hline gene-nrt2 & Nitrate transport 2 & 3.42 & $\begin{array}{l}3.66 \mathrm{E}- \\
03\end{array}$ & 3.56 & $\begin{array}{l}1.26 \mathrm{E}- \\
04\end{array}$ & up \\
\hline gene-nrt2.2 & High affinity nitrate transporter & 3.14 & $\begin{array}{l}7.32 \mathrm{E}- \\
04\end{array}$ & 3.68 & $\begin{array}{l}1.86 \mathrm{E}- \\
03\end{array}$ & up \\
\hline gene-HAK20 & Potassium transporter 5 & 3.00 & $\begin{array}{l}8.11 \mathrm{E}- \\
03\end{array}$ & 3.22 & $\begin{array}{l}3.36 \mathrm{E}- \\
03\end{array}$ & up \\
\hline gene-HAK21 & $\begin{array}{l}\text { Potassium transporter 21-like isoform } \\
\text { X1 }\end{array}$ & 4.87 & $\begin{array}{l}4.65 \mathrm{E}- \\
15\end{array}$ & 5.56 & $\begin{array}{l}3.72 \mathrm{E}- \\
03\end{array}$ & up \\
\hline gene-kup1 & Potassium ion uptake permease 1 & 3.06 & $\begin{array}{l}9.09 \mathrm{E}- \\
09\end{array}$ & 3.26 & $\begin{array}{l}4.70 \mathrm{E}- \\
03\end{array}$ & up \\
\hline
\end{tabular}

\section{Additional Files}

Additional file 1: Table S1. Characteristics of the RNA-sequencing data from six root samples of maize. 
Additional file 2: Table S2. The mapping results of RNA-seq clean reads from six root samples using the Z. mays genome of B73.

Additional file 3: Figure S1. COG database to classify the differentially expressed genes function and homology.

Additional file 4: Figure S2. KEGG pathway analysis to identify the differentially expressed genes functional categorization.

Additional file 5: Table S3. List of forward and reverse primers used for qRT-PCR analyses.

\section{Figures}

A

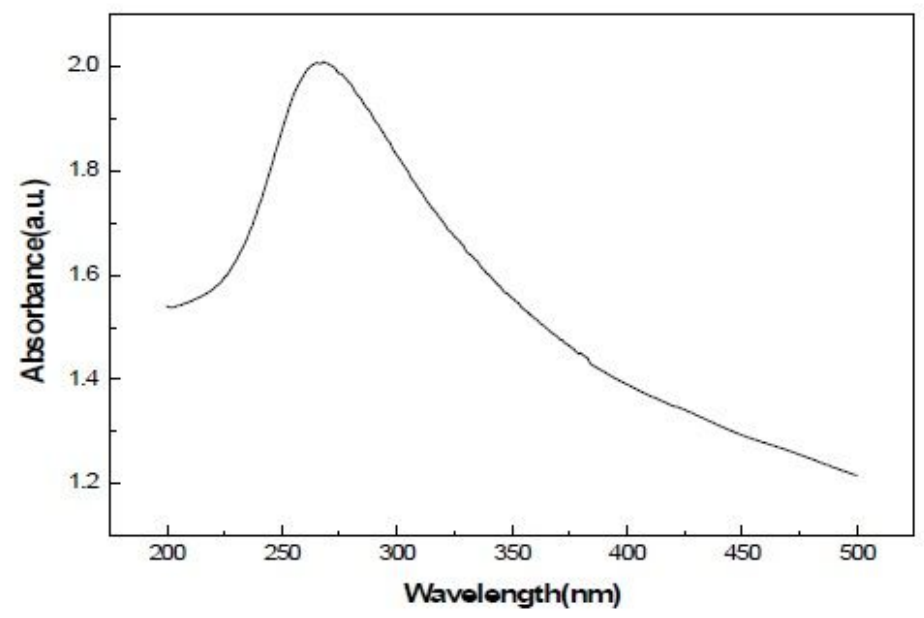

C

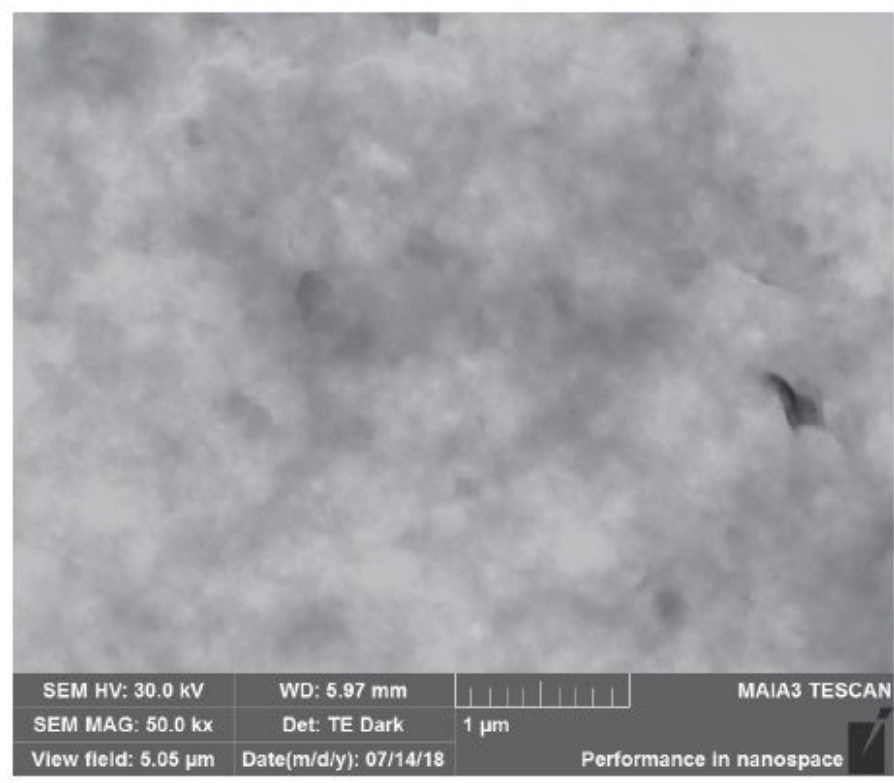

B

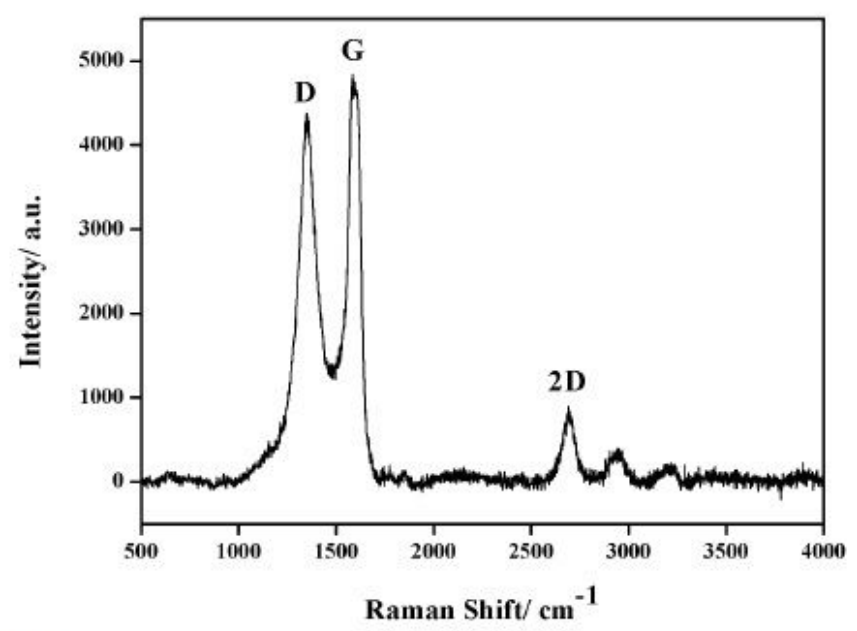

D

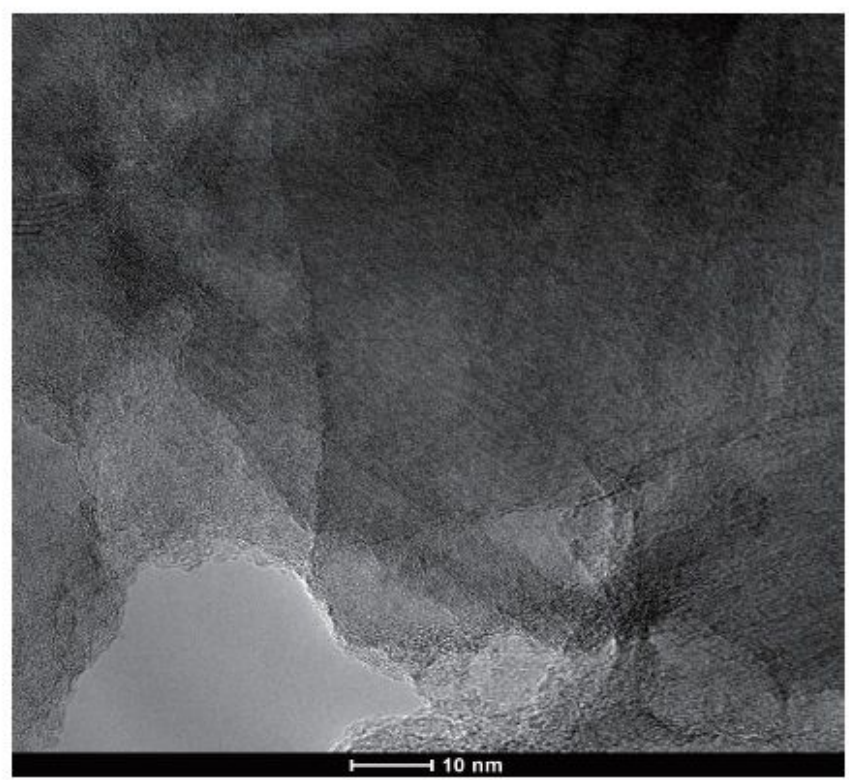

Figure 1 
Characterization of Graphene. (A): Ultraviolet-visible absorption spectrogram, (B): Raman spectra, (C): TEM image, and (D): TEM image.

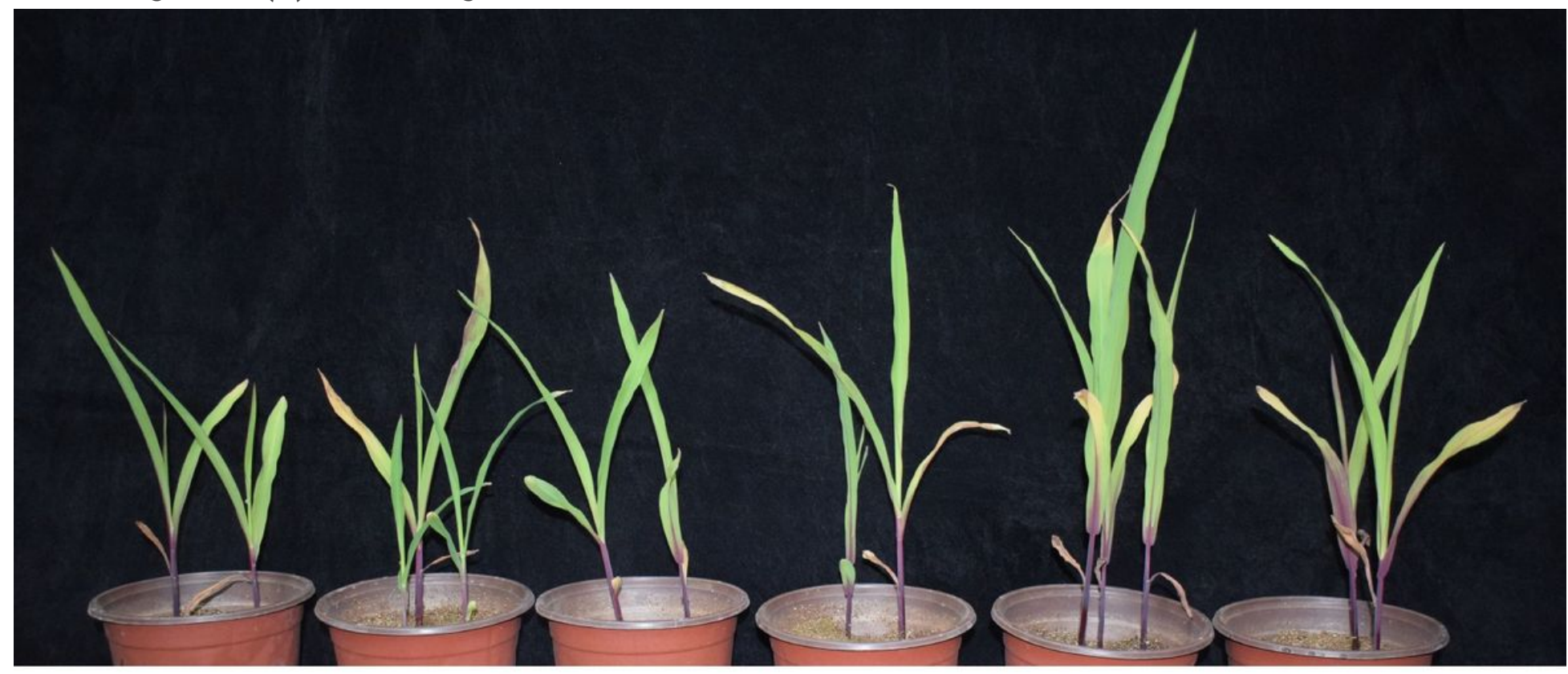

\section{$0 \mathrm{mg} / \mathrm{L} 20 \mathrm{mg} / \mathrm{L} 25 \mathrm{mg} / \mathrm{L} 33 \mathrm{mg} / \mathrm{L} \quad 50 \mathrm{mg} / \mathrm{L} \quad 100 \mathrm{mg} / \mathrm{L}$}

Figure 2

Phenotype of Zea mays seedlings with roots watering by six different concentrations of graphene. 
A

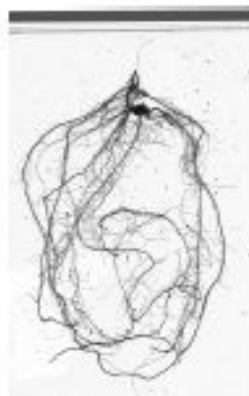

$0 \mathrm{mg} / \mathrm{L}$

B

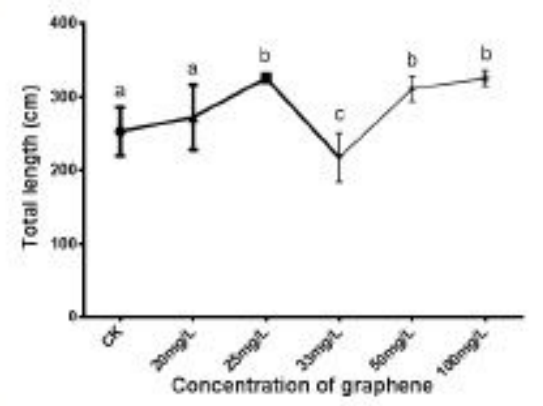

$\mathbf{E}$
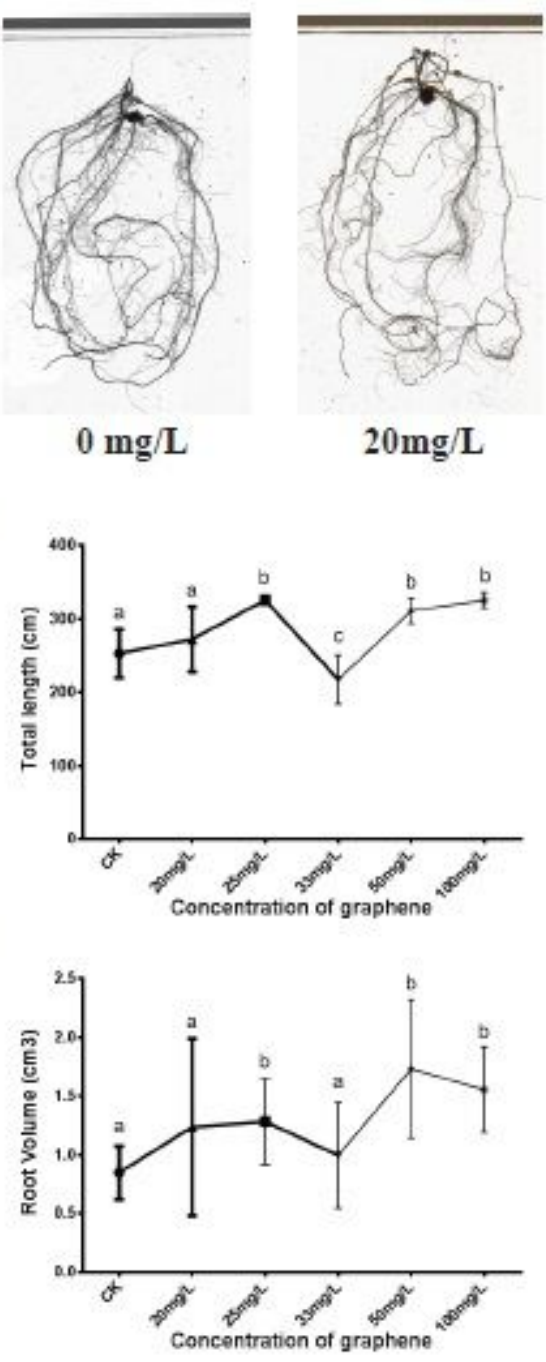

$20 \mathrm{mg} / \mathrm{L}$

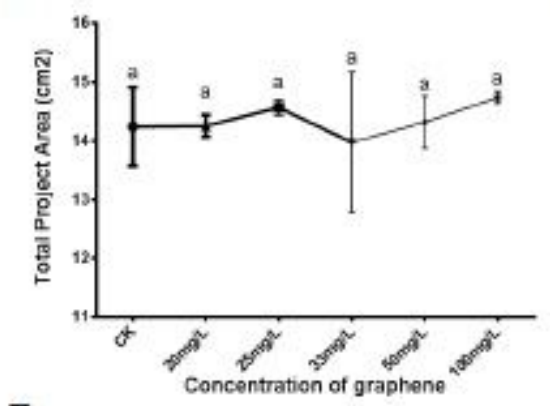

$\mathbf{F}$

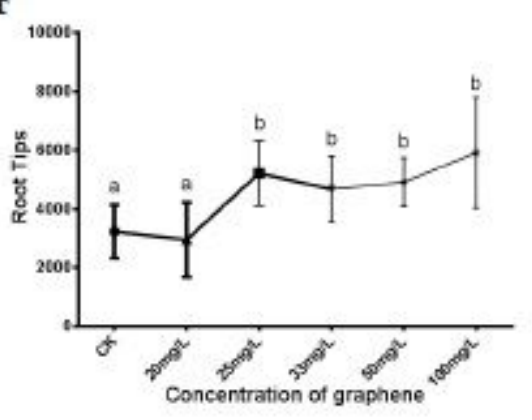

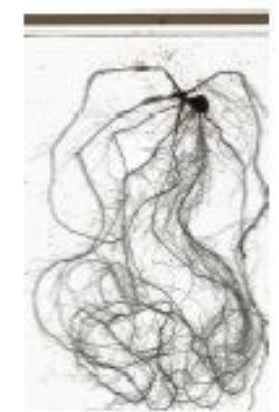

$50 \mathrm{mg} / \mathrm{L}$

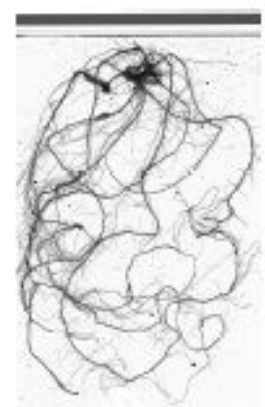

$100 \mathrm{mg} / \mathrm{L}$

D

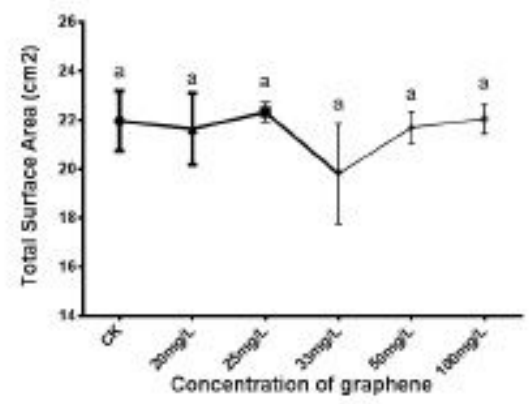

G

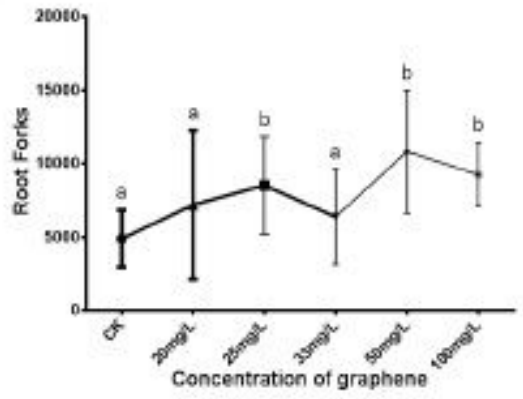

Figure 3

Root architecture analysis of maize seedlings under six concentration of graphene $(0,20,25,33,50$ and $100 \mathrm{mg} / \mathrm{L})$. (A): root morphology, (B): total root length, (C): total project area, (D): total surface area, (E): root volume, $(F)$ : the number of root tips, $(G)$ : the number of root forks. 
$\mathbf{A}$

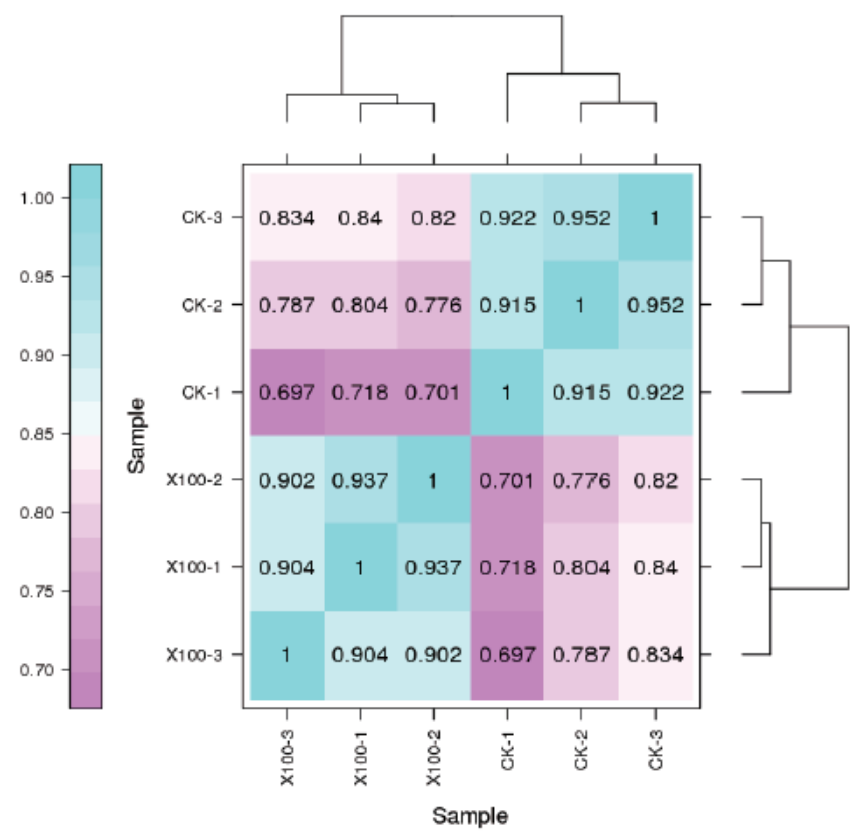

C

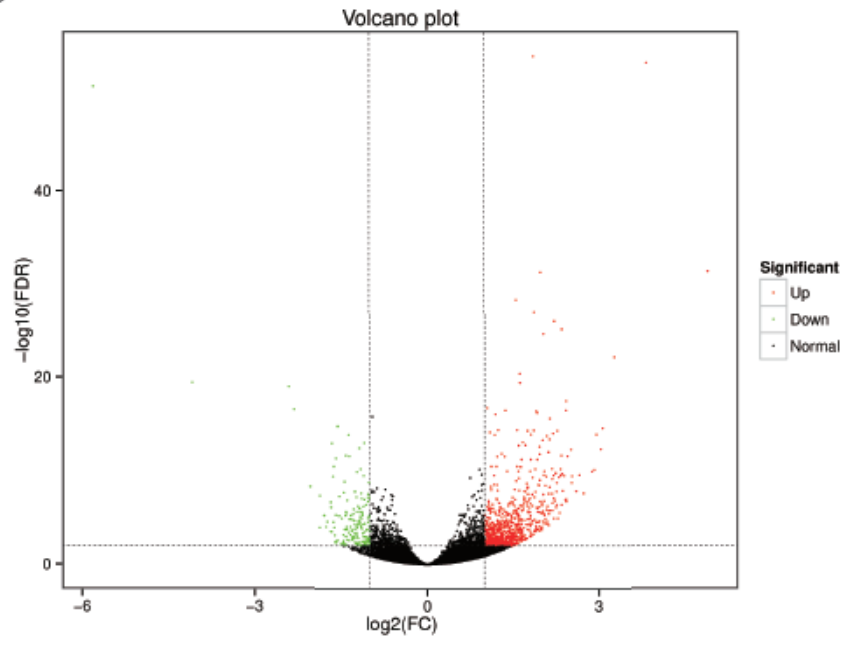

B

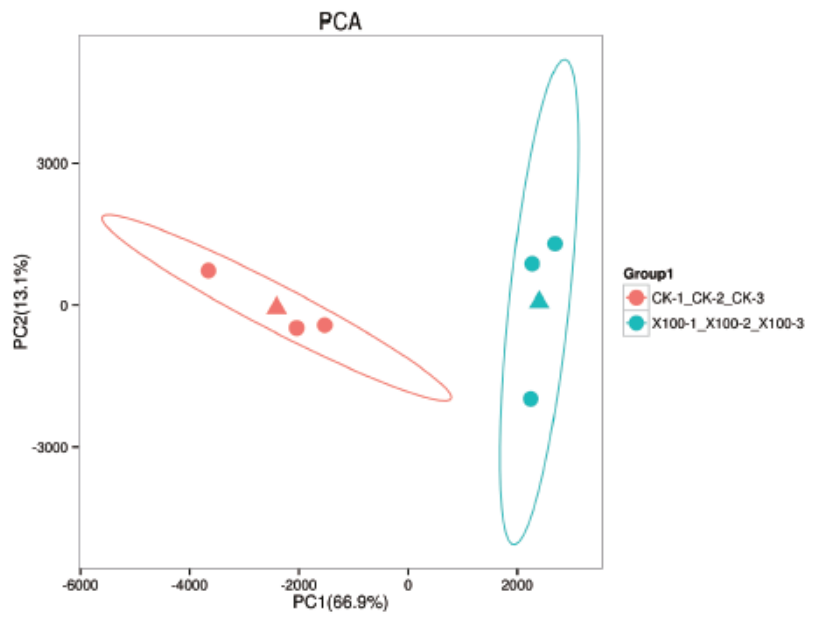

D

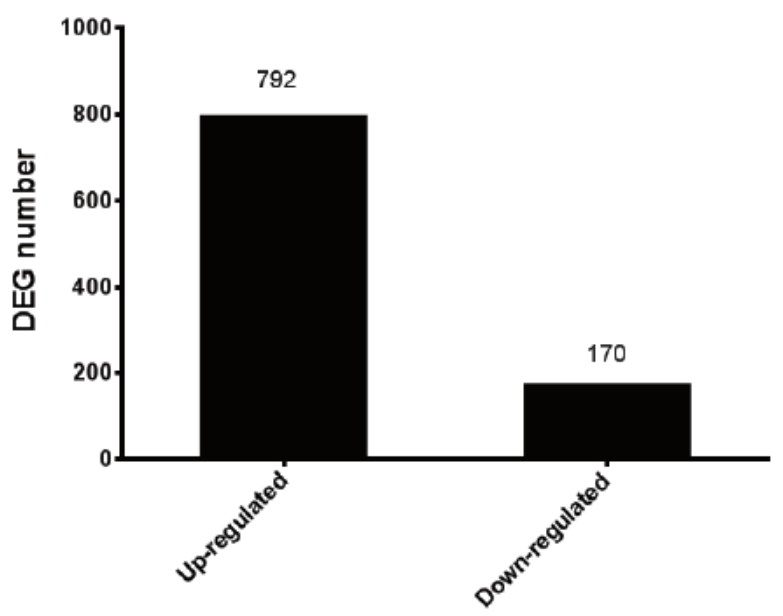

\section{Figure 4}

Overview of maize root transcriptome response to $50 \mathrm{mg} / \mathrm{L}$ graphene (X100) and CK. (A) Pearson correlation coefficient (PCC) of all the genes between six samples. (B) Principal component analysis of all samples. Red and light blue colors represent the samples of CK and exposed to $50 \mathrm{mg} / \mathrm{L}$ graphene, respectively. (C) Volcano plot of differentially expressed genes. (D) The number of up and down-regulated expressed genes. 


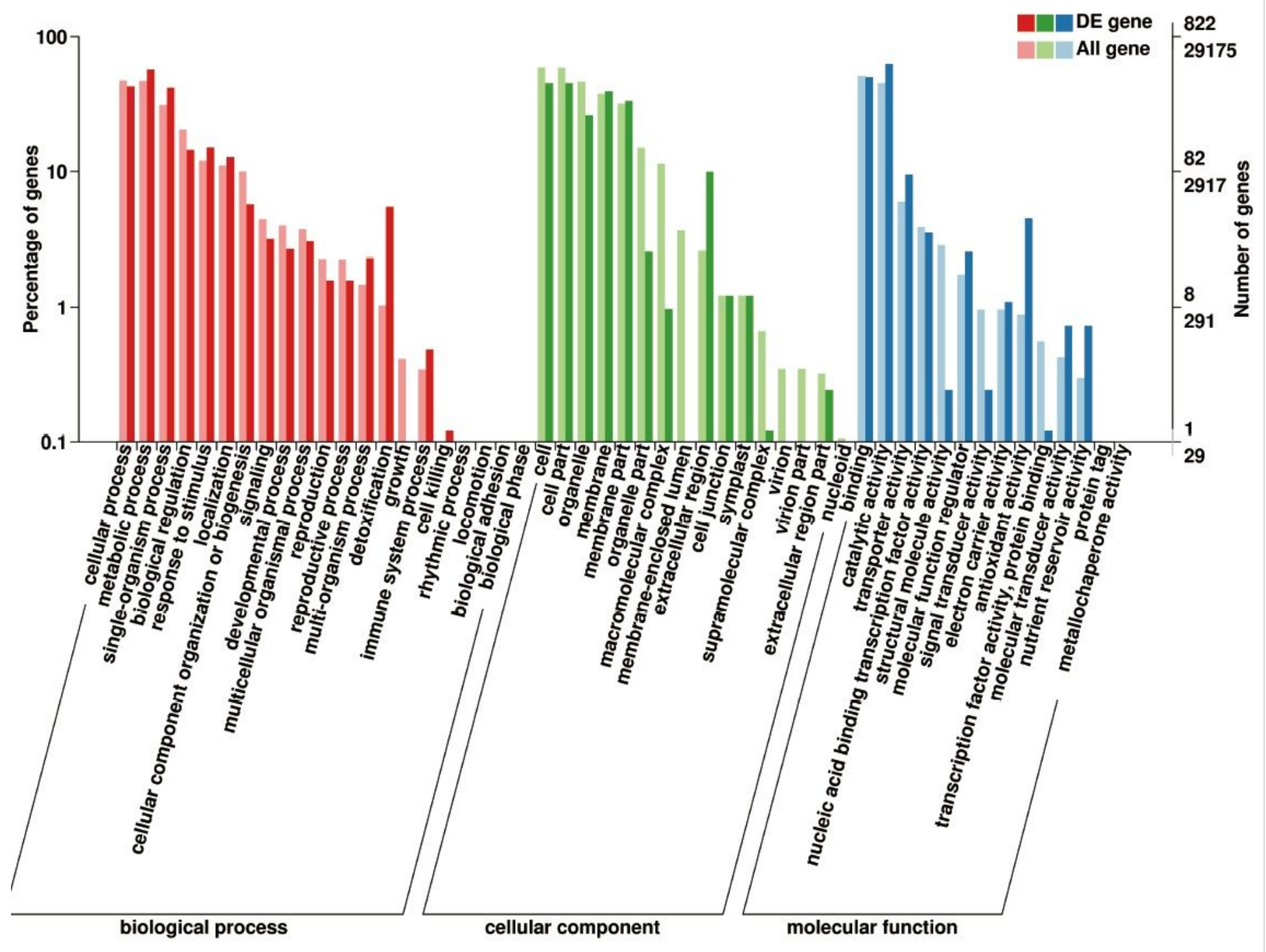

Figure 5

Gene ontology (GO) enrichment analysis of differentially expressed genes exposure to graphene. 
A

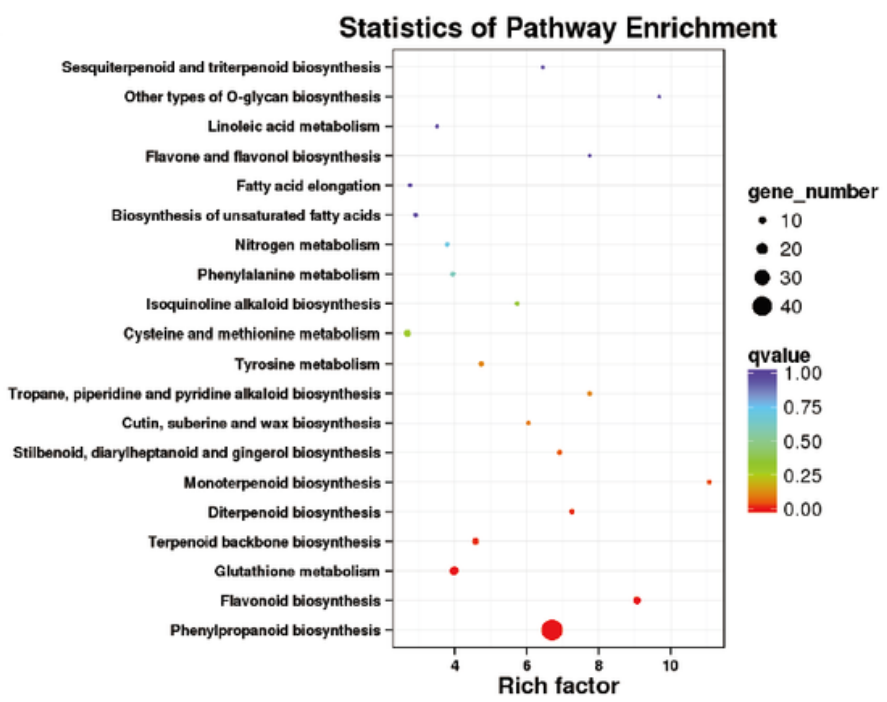

B

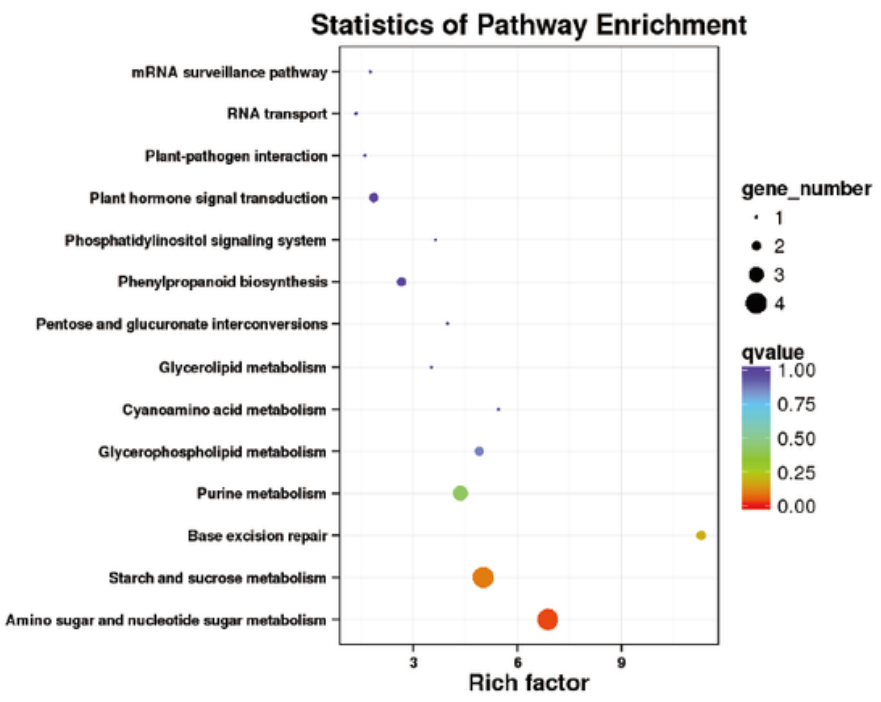

Figure 6

KEGG pathway analysis of differentially expressed genes enriched. (A) Top 20 pathways of significantly up- (left) and (B) 14 pathways of significantly down- (right) regulated genes enriched.

A

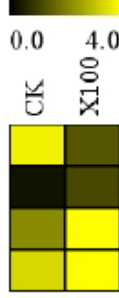

FPKM values

ERF TFs

gene-LOC103630375

gene-LOC103633756

gene-LOC103634250

gene-LOC103635988

D

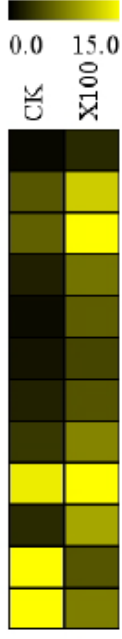

FPKM values

MYB and MYB-like TFs

gene-LOC100281236

gene-LOC100283628

gene-LOC100193483

gene-LOC 541743

gene-LOC 541744

gene-LOC 541753

gene-MYB64

gene-cl10996 1(617)

gene-myb42

gene-myb8

gene-LOC103642011
gene-RADIALIS
B

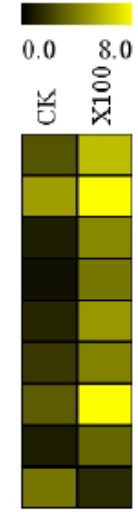

E

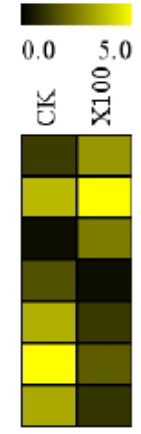

FPKM values

WRKY TFS

gene-LOC100282240

gene-LOC103630663

gene-LOC103639796

gene-LOC103648003

gene-LOC103649650

gene-LOC103649651

gene-LOC103651266

gene-LOC103652912

gene-WRKY45

FPKM values

\section{NAC TFs}

gene-LOC103625838

gene-LOC100502408

gene-LOC103633674

gene-LOC103653847

gene-LOC103654139

gene-LOC100217205

Zea_mays_newGene_17648
C 0.0 FRM values

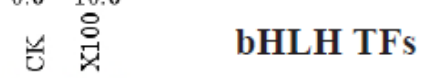

gene-LOC100285058

gene-LOC103630140

gene-LOC103634934

gene-LOC103649622

gene-bHLH94

gene-LOC103631852

F $\quad$ FPKM values

0.025 .0
$\times \quad 8$

늠

AP2 TFs

gene-EREB60

gene-EREB68

gene-LOC100191919

gene-LOC109944961

G $\quad 0.0 \quad 28.0$ FPKM values

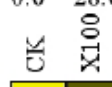

MADS-box TFs

gene-LOC100282492

gene-LOC103628959

Figure 7

Differentially expressed transcription factor (TF) genes between CK and graphene treatment of root samples in Zea mays. The colored bars represent the FPKM values of the DEGs. (A): ERF, (B): WRKY, (C): 
bHLH, (D): MYB and MYB-like, (E): NAC, (F): AP2, (G): MADS-box.

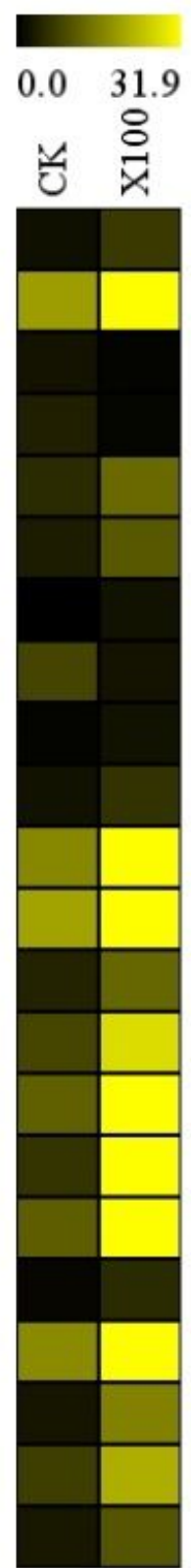

FPKM values

gene-LOC 100281448 gene-LOC100191976 gene-LOC103642166 gene-PIN5c

gene-cko1

gene-LOC100280143 gene-LOC100282611 gene-LOC 103646208 gene-LOC100282074 gene-LOC 100283080 gene-LOC 100283652 gene-LOC 100284800 gene-gar1

gene-LOC100281233 gene-LOC 100283794 gene-LOC103629478 gene-LOC103644149 gene-LOC103650571 gene-cl20570_1(540) gene-LOC $100 \overline{27} 3620$ gene-LOC 103636584 gene-LOC103630801

Auxin metabolism genes

Cytokinin (CK) metabolism genes

Gibberellin (GA) metabolism genes

Brassinosteroid (BR) metabolism genes

Jasmonate (JA) metabolism genes

Salicylic acid (SA) metabolism genes Strigolactone (SL) metabolism genes

Figure 8

Differentially expressed genes involved in hormones signaling pathways. 
A

FPKM values

ㄴ $\stackrel{\circ}{\circ}$ Nitrogen metabolism genes

gene-GLN6

gene-LOC100384578

gene-gln 3

gene-nit2

gene-nrt2.2

D FPKM values

$0.0 \quad 12.5$

굴

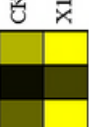

gene-HAK20

gene-HAK21

gene-kup 1
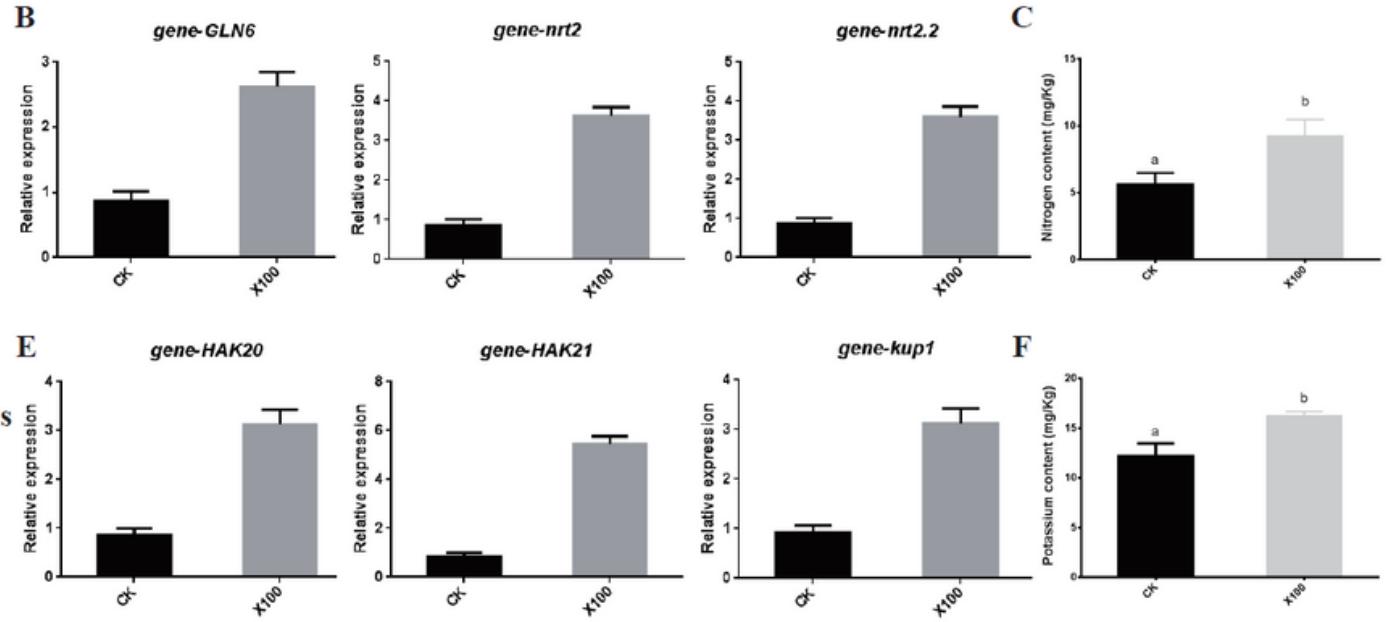

\section{Figure 9}

Up-regulated expression of genes involved in nitrogen and potassium metabolism. (A): Nitrogen metabolism gene expression profile of RNA-seq data. (B): Validation of the nitrogen metabolism gene expression by qRT-RCR. (C): Content of nitrogen in the soil around the maize seedling roots of $\mathrm{CK}$ and 50 $\mathrm{mg} / \mathrm{L}$ graphene treatments. Values are mean $\pm S E(n=5) . p<0.05$ by students T-test. (D): Potassium metabolism gene expression profile of RNA-seq data. (E): Validation of the potassium metabolism gene expression by qRT-RCR. (F) Content of potassium in the soil around the maize seedling roots of CK and $50 \mathrm{mg} / \mathrm{L}$ graphene treatments. Values are mean $\pm S E(n=5)$. $p<0.05$ by students T-test. 


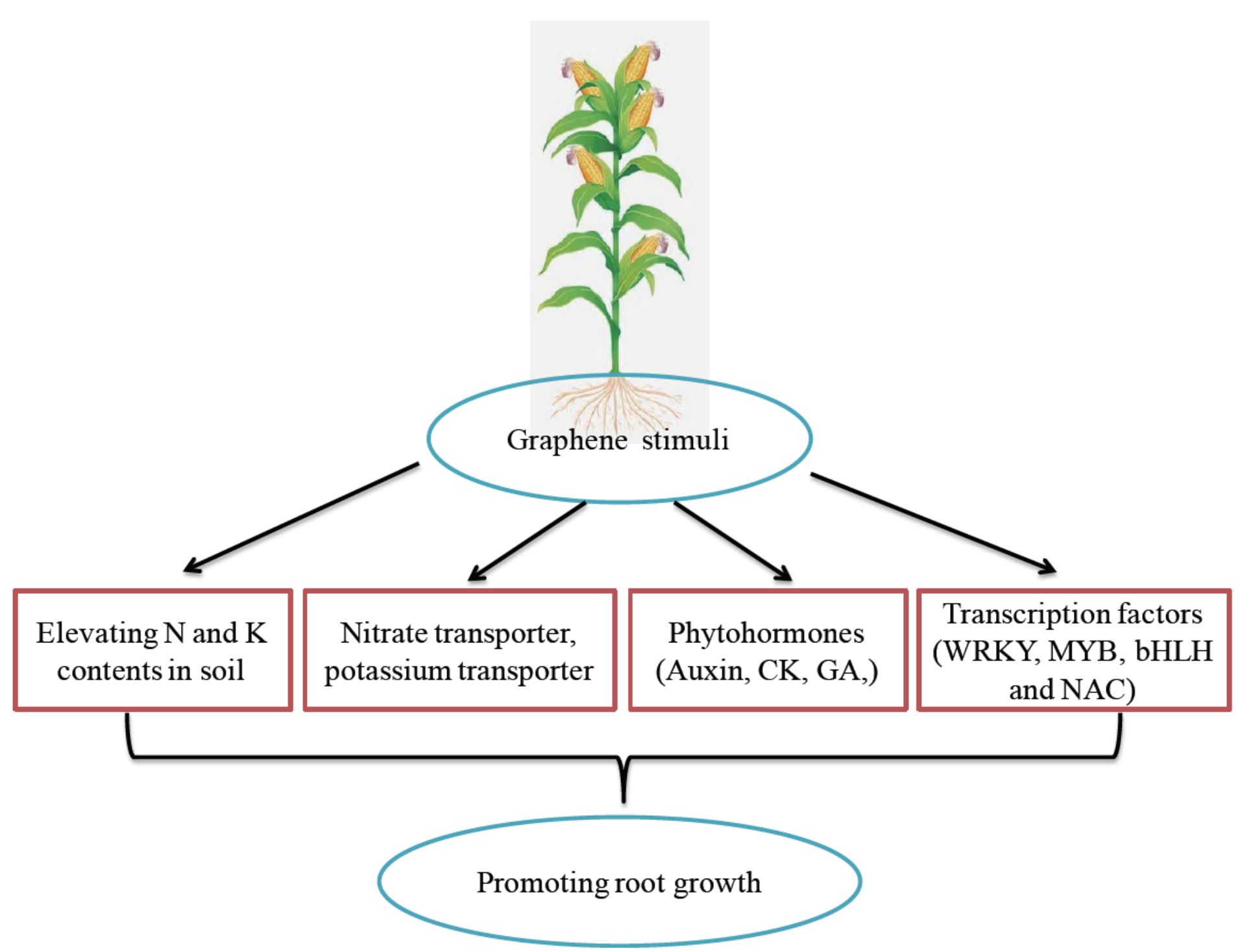

Figure 10

The putative model of the graphene in promoting maize roots development.

\section{Supplementary Files}

This is a list of supplementary files associated with this preprint. Click to download.

- Additionalfile4Figures2.pdf

- Additionalfile2TableS2.docx

- Additionalfile5Tables3.docx

- Additionalfile1Tables1.docx

- Additionalfile3Figures1.pdf 